Cochrane Database of Systematic Reviews

\title{
Non-pharmacological interventions for chronic pain in multiple sclerosis (Review)
}

Amatya B, Young J, Khan F

Amatya B, Young J, Khan F.

Non-pharmacological interventions for chronic pain in multiple sclerosis.

Cochrane Database of Systematic Reviews 2018, Issue 12. Art. No.: CD012622.

DOI: 10.1002/14651858.CD012622.pub2.

www.cochranelibrary.com

Non-pharmacological interventions for chronic pain in multiple sclerosis (Review) 
HEADER

ABSTRACT

PLAIN LANGUAGE SUMMARY

SUMMARY OF FINDINGS

BACKGROUND

OBJECTIVES

METHODS

RESULTS

Figure 1.

Figure 2.

Figure 3.

DISCUSSION

AUTHORS' CONCLUSIONS

ACKNOWLEDGEMENTS

REFERENCES

CHARACTERISTICS OF STUDIES

APPENDICES

CONTRIBUTIONS OF AUTHORS

DECLARATIONS OF INTEREST

SOURCES OF SUPPORT

DIFFERENCES BETWEEN PROTOCOL AND REVIEW

INDEX TERMS

\section{TABLE OF CONTENTS}

1

1

2

3

10

11

11

14

15

17

18

20

21

21

22

27

42

46

46

46

46

46 
[Intervention Review]

\section{Non-pharmacological interventions for chronic pain in multiple sclerosis}

Bhasker Amatya ${ }^{1}$, Jamie Young 2 , Fary Khan ${ }^{1}$

1Department of Rehabilitation Medicine, Royal Melbourne Hospital, Royal Park Campus, Melbourne, Australia. 2Rehabilitation Medicine, Melbourne Health, Melbourne, Australia

Contact address: Bhasker Amatya, Department of Rehabilitation Medicine, Royal Melbourne Hospital, Royal Park Campus, Poplar Road, Parkville, Melbourne, Victoria, 3052, Australia.Bhasker.Amatya@mh.org.au.

Editorial group: Cochrane Multiple Sclerosis and Rare Diseases of the CNS Group.

Publication status and date: New, published in Issue 12, 2018.

Citation: Amatya B, Young J, Khan F. Non-pharmacological interventions for chronic pain in multiple sclerosis. Cochrane Database of Systematic Reviews 2018, Issue 12. Art. No.: CD012622. DOI: 10.1002/14651858.CD012622.pub2.

Copyright @ 2018 The Cochrane Collaboration. Published by John Wiley \& Sons, Ltd.

\section{A B S T R A C T}

\section{Background}

Chronic pain is common and significantly impacts on the lives of persons with multiple sclerosis (pwMS). Various types of nonpharmacological interventions are widely used, both in hospital and ambulatory/mobility settings to improve pain control in pwMS, but the effectiveness and safety of many non-pharmacological modalities is still unknown.

\section{Objectives}

This review aimed to investigate the effectiveness and safety of non-pharmacological therapies for the management of chronic pain in pwMS. Specific questions to be addressed by this review include the following.

Are non-pharmacological interventions (unidisciplinary and/or multidisciplinary rehabilitation) effective in reducing chronic pain in pwMS?

What type of non-pharmacological interventions (unidisciplinary and/or multidisciplinary rehabilitation) are effective (least and most effective) and in what setting, in reducing chronic pain in pwMS?

\section{Search methods}

A literature search was performed using the specialised register of the Cochrane MS and Rare Diseases of the Central Nervous System Review Group, using the Cochrane MS Group Trials Register which contains CENTRAL, MEDLINE, Embase, CINAHL, LILACUS, Clinical trials.gov and the World Health Organization International Clinical Trials Registry Platform on 10 December 2017. Handsearching of relevant journals and screening of reference lists of relevant studies was carried out.

\section{Selection criteria}

All published randomised controlled trials (RCTs)and cross-over studies that compared non-pharmacological therapies with a control intervention for managing chronic pain in pwMS were included. Clinical controlled trials (CCTs) were eligible for inclusion.

\section{Data collection and analysis}

All three review authors independently selected studies, extracted data and assessed the methodological quality of the studies using the Grades of Recommendation, Assessment, Development and Evaluation (GRADE) tool for best-evidence synthesis. Pooling data for metaanalysis was not possible due to methodological, clinical and statistically heterogeneity of the included studies. 


\section{Main results}

Overall, 10 RCTs with 565 participants which investigated different non-pharmacological interventions for the management of chronic pain in MS fulfilled the review inclusion criteria. The non-pharmacological interventions evaluated included: transcutaneous electrical nerve stimulation (TENS), psychotherapy (telephone self-management, hypnosis and electroencephalogram (EEG) biofeedback), transcranial random noise stimulation (tRNS), transcranial direct stimulation (tDCS), hydrotherapy (Ai Chi) and reflexology.

There is very low-level evidence for the use of non-pharmacological interventions for chronic pain such as TENS, Ai Chi, tDCS, tRNS, telephone-delivered self-management program, EEG biofeedback and reflexology in pain intensity in pwMS. Although there were improved changes in pain scores and secondary outcomes (such as fatigue, psychological symptoms, spasm in some interventions), these were limited by methodological biases within the studies.

\section{Authors' conclusions}

Despite the use of a wide range of non-pharmacological interventions for the treatment of chronic pain in pwMS, the evidence for these interventions is still limited or insufficient, or both. More studies with robust methodology and greater numbers of participants are needed to justify the effect of these interventions for the management of chronic pain in pwMS.

\section{PLAIN LANGUAGE SUMMARY}

\section{[Non-pharmacological interventions for chronic pain in multiple sclerosis]}

\section{Review Question}

Do non-medication treatments improve chronic pain in multiple sclerosis (MS) in comparison to inactive treatment?

\section{Background}

Chronic pain in people with MS (pwMS) is common, and treatment with medications can be associated with and limited by side effects such as confusion, falls, dizziness and drowsiness. Many non-medication treatments are used to treat chronic pain in pwMS, which include exercise, psychology, electrical stimulation therapy, reflexology and others.

\section{Search Date}

We included all randomised clinical trials (clinical studies where people are randomly put into one of two or more intervention groups), which were published up to December 2017.

\section{Study Characteristics}

Overall, we found 10 studies evaluating different non-medication treatments to treat chronic pain in persons with MS. The treatments evaluated included: transcutaneous electrical nerve stimulation, transcranial direct stimulation, transcranial random noise stimulation, reflexology, psychotherapy and hydrotherapy. These studies included 565 participants and used a range of different methods to measure pain and other outcomes. Comparison groups also varied.

\section{Key Results}

Results from these studies show a very low level of evidence for the use of any non-medication treatments for chronic pain in persons with MS.

\section{Quality of Evidence}

We assessed the overall quality of the studies as very low, as many studies included only small numbers of participants and had other methodological issues. More research with good methodological quality and greater number of participants are needed to determine the effectiveness of such treatments. 


\section{SUMMARY OF FINDINGS}

Summary of findings for the main comparison. Transcutaneous Electrical Nerve Stimulation (TENS) compared to Sham for Chronic Back Pain in Multiple Sclerosis (MS)

\section{Transcutaneous electrical nerve stimulation (TENS) compared to sham for chronic back pain in MS}

Patient or population: chronic back pain in MS

Setting: participants from Multiple Sclerosis Society in Northern Ireland

Intervention: TENS

Comparison: sham

\begin{tabular}{|c|c|c|c|}
\hline Outcomes & Impact & $\begin{array}{l}\text { № of participants } \\
\text { (studies) }\end{array}$ & $\begin{array}{l}\text { Certainty of the } \\
\text { evidence } \\
\text { (GRADE) }\end{array}$ \\
\hline $\begin{array}{l}\text { Reduction in pain } \\
\text { intensity } \\
\text { assessed with: VAS, } \\
\text { MPQ }\end{array}$ & $\begin{array}{l}\text { Decrease in low back pain scores overtime for all groups, how- } \\
\text { ever, none reached clinical or statistical significance in VAS } \\
\text { scores. No statistically significant changes in MPQ (Warke 2006). } \\
\text { VAS mean reduction for TENS low frequency at week } 6 \text { was } \\
\text {-16.59 (weekly low back pain) and - } 19.76 \text { (average low back } \\
\text { pain). }\end{array}$ & $\begin{array}{l}90 \\
(1 \mathrm{RCT})\end{array}$ & $\begin{array}{l}\oplus \odot \ominus \ominus \\
\text { VERY LOW } 1,2\end{array}$ \\
\hline $\begin{array}{l}\text { Reduction in dis- } \\
\text { ability } \\
\text { assessed with: } \\
\text { RMDQ, BI }\end{array}$ & $\begin{array}{l}\text { No significant changes in disability measured by RMDQ and } \\
\text { BI between treatment and placebo groups and within-groups } \\
\text { (Warke 2006). }\end{array}$ & $\begin{array}{l}90 \\
(1 \mathrm{RCT})\end{array}$ & $\begin{array}{l}\oplus \odot \odot \odot \\
\text { VERY LOW } 1,2\end{array}$ \\
\hline $\begin{array}{l}\text { Quality of Life } \\
\text { assessed with: } \\
\text { LMSQoLQ, SF-36 }\end{array}$ & $\begin{array}{l}\text { No significant difference in quality of life measured by } \\
\text { LMSQoLQ or SF-36 between treatment and placebo groups } \\
\text { (Warke 2006). }\end{array}$ & $\begin{array}{l}90 \\
(1 \mathrm{RCT})\end{array}$ & $\begin{array}{l}\oplus \odot \odot \odot \\
\text { VERY LOW } 1,2\end{array}$ \\
\hline
\end{tabular}

BI: Barthel Index; MPQ: McGill Pain Questionnaire; LMSQoLQ: Leeds Multiple Sclerosis Quality of Life Questionnaire; RMDQ: Roland Morris Disability Questionnaire; SF-36: Short Form 36; VAS: Visual Analogue Scale

\section{GRADE Working Group grades of evidence}

High certainty: We are very confident that the true effect lies close to that of the estimate of the effect

Moderate certainty: We are moderately confident in the effect estimate: The true effect is likely to be close to the estimate of the effect, but there is a possibility that it is substantially different

Low certainty: Our confidence in the effect estimate is limited: The true effect may be substantially different from the estimate of the effect

Very low certainty: We have very little confidence in the effect estimate: The true effect is likely to be substantially different from the estimate of effect

1Downgraded two levels due to high risk for bias (unclear allocation concealment)

2Downgraded two levels due to high risk of bias for imprecision (singular study of small sample size)

\section{Summary of findings 2. Ai Chi Exercises compared to Sham for Chronic Musculoskeletal pain in Multiple Sclerosis} (MS)

\section{Ai Chi exercises compared to sham for chronic musculoskeletal pain in multiple sclerosis}

Patient or population: chronic musculoskeletal pain in people with MS

Setting: participants were recruited from MS Association of Almeria in Spain

Intervention: $\mathrm{Ai}$ Chi exercises 
Comparison: sham

\begin{tabular}{|c|c|c|c|}
\hline Outcomes & Impact & $\begin{array}{l}\text { № of participants } \\
\text { (studies) }\end{array}$ & $\begin{array}{l}\text { Certainty of the } \\
\text { evidence } \\
\text { (GRADE) }\end{array}$ \\
\hline $\begin{array}{l}\text { Reduction in pain } \\
\text { intensity } \\
\text { assessed with: VAS, } \\
\text { MPQ }\end{array}$ & $\begin{array}{l}\text { Significant reduction in pain scores measured by VAS in the } \\
\text { treatment group immediately after treatment and no signif- } \\
\text { icant change from baseline in the control group. Pain VAS at } \\
\text { week } 20 \text { was } 50 \% \text { (experimental) and } 23 \% \text { (control). } \\
\text { Significant pain reduction for MPQ in the treatment group and } \\
\text { no significant change from baseline in the control group (Cas- } \\
\text { tro-Sanchez 2012). }\end{array}$ & $\begin{array}{l}73 \\
(1 \mathrm{RCT})\end{array}$ & $\begin{array}{l}\oplus \odot \ominus \ominus \\
\text { VERY LOW } 1,2\end{array}$ \\
\hline $\begin{array}{l}\text { Reduction in dis- } \\
\text { ability } \\
\text { assessed with: } \\
\text { RMDQ }\end{array}$ & $\begin{array}{l}\text { Significant reduction in disability measured by RMDQ in inter- } \\
\text { vention and control group at week } 20 \text { (Castro-Sanchez 2012). }\end{array}$ & $\begin{array}{l}73 \\
(1 \mathrm{RCT})\end{array}$ & $\begin{array}{l}\oplus \Theta \Theta \odot \\
\text { VERY LOW } 1,2\end{array}$ \\
\hline $\begin{array}{l}\text { Quality of Life } \\
\text { assessed with: } \\
\text { MSIS-29 }\end{array}$ & $\begin{array}{l}\text { Both groups showed a significant reduction in the psychologi- } \\
\text { cal sub scale of the MFIS at week } 20 \text {. Treatment group showed } \\
\text { significant score reduction but the control group showed no } \\
\text { significant difference with baseline score in the physical sub } \\
\text { scale at week } 20 \text { (Castro-Sanchez 2012). }\end{array}$ & $\begin{array}{l}73 \\
(1 \mathrm{RCT})\end{array}$ & $\begin{array}{l}\oplus \odot \odot \odot \\
\text { VERY LOW } 1,2\end{array}$ \\
\hline $\begin{array}{l}\text { Reduction in } \mathbf{F a -} \\
\text { tigue } \\
\text { assessed with:MFIS }\end{array}$ & $\begin{array}{l}\text { Treatment group showed a significant score reduction com- } \\
\text { pared with baseline at week } 20 \text {, but no significant difference } \\
\text { in control group. Treatment group showed a significant reduc- } \\
\text { tion in cognitive scale compared with the control group (Cas- } \\
\text { tro-Sanchez 2012). }\end{array}$ & $\begin{array}{l}73 \\
(1 \mathrm{RCT})\end{array}$ & $\begin{array}{l}\oplus \odot \Theta \odot \\
\text { VERY LOW } 1,2\end{array}$ \\
\hline
\end{tabular}

MFIS: Modified Fatigue Impact Scale; MPQ: McGill Pain Questionnaire; MSIS-29: Multiple Sclerosis Impact Scale-29; RMDQ: Roland Morris Disability Questionnaire, SF-36: Short Form 36; VAS: Visual Analogue Scale

\section{GRADE Working Group grades of evidence}

High certainty: We are very confident that the true effect lies close to that of the estimate of the effect

Moderate certainty: We are moderately confident in the effect estimate: The true effect is likely to be close to the estimate of the effect, but there is a possibility that it is substantially different

Low certainty: Our confidence in the effect estimate is limited: The true effect may be substantially different from the estimate of the effect

Very low certainty: We have very little confidence in the effect estimate: The true effect is likely to be substantially different from the estimate of effect

1 Downgraded two levels because the singular study was considered at serious risk of performance bias ( blinding of participants and personnel ) and unclear risk of allocation concealment

2 Downgraded two levels due to imprecision (small sample size)

\section{Summary of findings 3. Transcranial Direct Current Stimulation (tDCS) compared to Sham for Chronic Neuropathic Pain in Multiple Sclerosis (MS)}

Transcranial direct current stimulation (tDCS) compared to sham for chronic neuropathic pain in MS

Patient or population: chronic neuropathic pain in MS

Setting: community neurology clinic

Intervention: tDCS

Comparison: sham 


\begin{tabular}{|c|c|c|c|}
\hline Outcomes & Impact & $\begin{array}{l}\text { № of participants } \\
\text { (studies) }\end{array}$ & $\begin{array}{l}\text { Certainty of the } \\
\text { evidence } \\
\text { (GRADE) }\end{array}$ \\
\hline $\begin{array}{l}\text { Reduction in Pain } \\
\text { Intensity } \\
\text { assessed with: VAS, } \\
\text { BPI, MPQ }\end{array}$ & $\begin{array}{l}\text { Mean pain VAS showed significant decrease after active tDCS } \\
\text { (mean baseline 51.2; after treatment } 43.1 \text { ) but no significant } \\
\text { change after sham (mean baseline } 52.1 \text {; after treatment } 50.3 \text { ). } \\
\text { BPI global score for active tDCS resulted in significant improve- } \\
\text { ment on the interference sub scale but no significant effects on } \\
\text { the severity sub scale (Ayache } 2016 \text { ). } \\
\text { Significant main effect of time for decreased daily pain VAS } \\
\text { (Mori 2010). }\end{array}$ & $\begin{array}{l}35 \\
(2 \mathrm{RCTS})\end{array}$ & $\begin{array}{l}\oplus \odot \odot \odot \\
\text { VERY LOW } 1,2\end{array}$ \\
\hline $\begin{array}{l}\text { Reduction in fa- } \\
\text { tigue } \\
\text { assessed with: } \\
\text { MFIS }\end{array}$ & $\begin{array}{l}\text { There was no significant difference in fatigue measured by the } \\
\text { MFIS between groups (Ayache 2016). }\end{array}$ & $\begin{array}{l}16 \\
(1 \mathrm{RCT})\end{array}$ & $\begin{array}{l}\oplus \odot \odot \ominus \\
\text { VERY LOW } 1,2\end{array}$ \\
\hline $\begin{array}{l}\text { Reduction in de- } \\
\text { pression and anxi- } \\
\text { ety } \\
\text { assessed with: BDI, } \\
\text { HADS, VAS for anxi- } \\
\text { ety }\end{array}$ & $\begin{array}{l}\text { No significant differences in depression and anxiety were ob- } \\
\text { served for both groups on HADS (Ayache 2016). } \\
\text { No significant changes for BDI and VAS for anxiety with time as } \\
\text { within subjects and group of treatment as between subjects. } \\
\text { (Mori 2010) }\end{array}$ & $\begin{array}{l}35 \\
(2 \mathrm{RCTs})\end{array}$ & $\begin{array}{l}\oplus \odot \Theta \odot \\
\text { VERY LOW } 1,2\end{array}$ \\
\hline $\begin{array}{l}\text { Improvement in } \\
\text { QoL } \\
\text { assessed with: } \\
\text { MSQOL54 }\end{array}$ & $\begin{array}{l}\text { Significant effect of time and group x time interaction for im- } \\
\text { proved quality of life measured by the MSQOL54 (Mori 2010). }\end{array}$ & $\begin{array}{l}19 \\
(1 \mathrm{RCT})\end{array}$ & $\begin{array}{l}\oplus \odot \Theta \odot \\
\text { VERY LOW } 1,2\end{array}$ \\
\hline
\end{tabular}

BDI: Beck Depression Inventory; HADS: Hospital Anxiety and Depression Scale; MPQ: McGill Pain Questionnaire; MSQOL54: Multiple Sclerosis Quality of Life 54. QoL: Quality of life, VAS; Visual Analogue Scale

\section{GRADE Working Group grades of evidence}

High certainty: We are very confident that the true effect lies close to that of the estimate of the effect

Moderate certainty: We are moderately confident in the effect estimate: The true effect is likely to be close to the estimate of the effect, but there is a possibility that it is substantially different

Low certainty: Our confidence in the effect estimate is limited: The true effect may be substantially different from the estimate of the effect

Very low certainty: We have very little confidence in the effect estimate: The true effect is likely to be substantially different from the estimate of effect

1 Downgraded one level for risk for bias (the two studies at unclear risk of bias in allocation concealment)

2 Downgraded two levels for high risk for imprecision (small sample sizes of both studies)

\section{Summary of findings 4. Transcranial Random Noise Stimulation (tRNS)compared to Sham for Chronic Neuropathic} Pain in Multiple Sclerosis (MS)

Transcranial Random Noise Stimulation (tRNS) compared to sham for chronic neuropathic pain in MS

Patient or population: chronic neuropathic pain in MS

Setting: hospital MS clinics

Intervention: tRNS

Comparison: sham

\begin{tabular}{llll}
\hline Outcomes & Impact & № of participants & $\begin{array}{l}\text { Certainty of the } \\
\text { (studies) }\end{array}$
\end{tabular}

Non-pharmacological interventions for chronic pain in multiple sclerosis (Review) 


\begin{tabular}{|c|c|c|c|}
\hline & & & (GRADE) \\
\hline $\begin{array}{l}\text { Reduction in pain } \\
\text { assessed with: VAS, } \\
\text { BPI }\end{array}$ & $\begin{array}{l}\text { No statistically significant changes for mean pain VAS treat- } \\
\text { ment (mean VAS before } 50.1 \text {; mean } \\
\text { VAS after } 47.2 \text { ) and sham groups (mean VAS before: } 52.1 \text {; } \\
\text { mean VAS after:50.3). } \\
\text { No statistical significance before and after stimulation sham } \\
\text { and treatment for BPI (Palm 2016). }\end{array}$ & $\begin{array}{l}16 \\
(1 \mathrm{RCT})\end{array}$ & $\begin{array}{l}\oplus \Theta \Theta \Theta \\
\text { VERY LOW } 1,2\end{array}$ \\
\hline $\begin{array}{l}\text { Reduction in anxiety } \\
\text { and depression } \\
\text { assessed with: HADS }\end{array}$ & $\begin{array}{l}\text { No statistical significance before and after for treatment and } \\
\text { sham for mean HADS (Palm 2016). }\end{array}$ & $\begin{array}{l}16 \\
(1 \mathrm{RCT})\end{array}$ & $\begin{array}{l}\oplus \odot \Theta \odot \\
\text { VERY LOW } 1,2\end{array}$ \\
\hline $\begin{array}{l}\text { Reduction in fatigue } \\
\text { assessed with: MFIS }\end{array}$ & $\begin{array}{l}\text { No statistical significance before and after sham and treat- } \\
\text { ment for mean total score (Palm 2016). }\end{array}$ & $\begin{array}{l}16 \\
(1 \mathrm{RCT})\end{array}$ & $\begin{array}{l}\oplus \odot \odot \ominus \\
\text { VERY LOW } 1,2\end{array}$ \\
\hline
\end{tabular}

BPI: Beck Pain Inventory; HADS: Hospital Anxiety and Depression Scale; MFIS: Modified Fatigue Impact Scale; VAS; Visual Analogue Scale

\section{GRADE Working Group grades of evidence}

High certainty: We are very confident that the true effect lies close to that of the estimate of the effect

Moderate certainty: We are moderately confident in the effect estimate: The true effect is likely to be close to the estimate of the effect, but there is a possibility that it is substantially different

Low certainty: Our confidence in the effect estimate is limited: The true effect may be substantially different from the estimate of the effect

Very low certainty: We have very little confidence in the effect estimate: The true effect is likely to be substantially different from the estimate of effect

1 Downgraded two levels because the singular study was considered at high risk of bias (unclear risk of bias in randomisation sequence generation, allocation concealment and blinding of outcome assessors)

2 Downgraded two levels due to high risk for imprecision (singular study of small sample size)

\section{Summary of findings 5. Telephone-Delivered Education Group compared to Sham for Chronic pain in Multiple Sclerosis (MS)}

\section{Telephone-delivered education compared to sham for chronic pain in MS}

Patient or population: chronic pain in MS

Setting: participants' home across United States

Intervention: telephone-delivered education group

Comparison: sham

\begin{tabular}{|c|c|c|c|}
\hline Outcomes & Impact & $\begin{array}{l}\text { № of participants } \\
\text { (studies) }\end{array}$ & $\begin{array}{l}\text { Certainty of the } \\
\text { evidence } \\
\text { (GRADE) }\end{array}$ \\
\hline $\begin{array}{l}\text { Reduction in pain interference, depression,fa- } \\
\text { tigue } \\
\text { assessed with: BPI, PHQ-9, MFIS }\end{array}$ & $\begin{array}{l}58 \% \text { of telephone self-management } \\
\text { group and } 46 \% \text { of telephone educa- } \\
\text { tion group had }>50 \% \text { reduction in } \\
1 \text { or more symptoms (fatigue, pain, } \\
\text { depression), but not statistically sig- } \\
\text { nificant (Ehde 2015). }\end{array}$ & $\begin{array}{l}163 \\
\text { (1 RCT) }\end{array}$ & $\begin{array}{l}\oplus \odot \odot \ominus \\
\text { VERY LOW } 1,2\end{array}$ \\
\hline $\begin{array}{l}\text { Improvement in pain, self efficacy,patient ac- } \\
\text { tivation, health-related quality of life, social } \\
\text { role satisfaction,resilience,positive and nega- } \\
\text { tive affect }\end{array}$ & $\begin{array}{l}\text { Statistically significant improve- } \\
\text { ments in all secondary outcomes for } \\
\text { fatigue, pain interference, self effi- }\end{array}$ & $\begin{array}{l}163 \\
(1 \mathrm{RCT})\end{array}$ & $\begin{array}{l}\oplus \odot \odot \odot \\
\text { VERY LOW 1, } 2\end{array}$ \\
\hline
\end{tabular}


assessed with: Average Pain Intensity, UWSES, Patient Activation Measure, Medical Outcomes Study 8 Item Short Form Heath Survey, Patient Reported Outcomes Measurement Information System Short-Form, Connor-Davidson Resilience Scale cacy and QoLcompared with tele-

phone education group (Ehde 2015).

BPI: Brief Pain Inventory; MFIS: Modified Fatigue Impact Scale; MPQ: McGill Pain Questionnaire; PHQ-9:Patient Health Questionnaire 9; QoL: quality of life; UWSES:University of Washington Self Efficacy Scale

\section{GRADE Working Group grades of evidence}

High certainty: We are very confident that the true effect lies close to that of the estimate of the effect

Moderate certainty: We are moderately confident in the effect estimate: The true effect is likely to be close to the estimate of the effect, but there is a possibility that it is substantially different

Low certainty: Our confidence in the effect estimate is limited: The true effect may be substantially different from the estimate of the effect

Very low certainty: We have very little confidence in the effect estimate: The true effect is likely to be substantially different from the estimate of effect

1 Downgraded two levels due to high risk of bias (the singular study at high risk of bias in blinding of outcome assessor and attrition)

2 Downgraded two levels due to high risk of bias for imprecision (small sample size)

\section{Summary of findings 6 . Hypnosis compared to relaxation control for chronic pain in Multiple Sclerosis (MS)}

\section{Hypnosis compared to relaxation/control for chronic pain in MS}

Patient or population: chronic pain in MS

Setting: MS clinics

Intervention: hypnosis

Comparison: relaxation/control

\begin{tabular}{|c|c|c|c|}
\hline Outcomes & Impact & $\begin{array}{l}\text { № of participants } \\
\text { (studies) }\end{array}$ & $\begin{array}{l}\text { Certainty of the } \\
\text { evidence } \\
\text { (GRADE) }\end{array}$ \\
\hline $\begin{array}{l}\text { Reduction in pain inten- } \\
\text { sity } \\
\text { assessed with: Average } \\
\text { Pain Intensity, Daily Pain } \\
\text { Intensity (Numeric Rating } \\
\text { Scale) }\end{array}$ & $\begin{array}{l}\text { Statistically significant changes pre and post treatment } \\
\text { for hypnosis group but not in progressive relaxation } \\
\text { group. Statistically significant decrease in daily/average } \\
\text { pain scores for the self hypnosis group but not significant } \\
\text { in the progressive muscle relaxation group (Jensen 2009). }\end{array}$ & $\begin{array}{l}22 \\
(1 \mathrm{RCT})\end{array}$ & $\begin{array}{l}\oplus \odot \odot \odot \\
\text { VERY LOW } 1,2\end{array}$ \\
\hline $\begin{array}{l}\text { Reduction in pain inter- } \\
\text { ference } \\
\text { assessed with: BPI }\end{array}$ & $\begin{array}{l}\text { Statistically significant change pre to post treatment in } \\
\text { the hypnosis group but not in the progressive relaxation } \\
\text { group (Jensen 2009). }\end{array}$ & $\begin{array}{l}22 \\
(1 \mathrm{RCT})\end{array}$ & $\begin{array}{l}\oplus \odot \odot \ominus \\
\text { VERY LOW 1, } 2\end{array}$ \\
\hline
\end{tabular}

BPI: Brief Pain Inventory

\section{GRADE Working Group grades of evidence}

High certainty: We are very confident that the true effect lies close to that of the estimate of the effect

Moderate certainty: We are moderately confident in the effect estimate: The true effect is likely to be close to the estimate of the effect, but there is a possibility that it is substantially different

Low certainty: Our confidence in the effect estimate is limited: The true effect may be substantially different from the estimate of the effect

Very low certainty: We have very little confidence in the effect estimate: The true effect is likely to be substantially different from the estimate of effect 
1 Downgraded two levels due to high risk for bias (the singular study did not describe whether blinding had occurred for participants)

2 Downgraded two levels due to high risk for imprecision (singular study of small sample size)

Summary of findings 7. Neurofeedback compared to relaxation control for chronic pain in Multiple Sclerosis (MS)

Neurofeedback compared to relaxation/control for chronic pain in MS

Patient or population: chronic pain in MS

Setting: MS clinics

Intervention: neurofeedback

Comparison: relaxation/control

\begin{tabular}{|c|c|c|c|}
\hline Outcomes & Impact & $\begin{array}{l}\text { № of participants } \\
\text { (studies) }\end{array}$ & $\begin{array}{l}\text { Certainty of the } \\
\text { evidence } \\
\text { (GRADE) }\end{array}$ \\
\hline $\begin{array}{l}\text { Reduction in pain In- } \\
\text { tensity } \\
\text { assessed with: Nu- } \\
\text { merical Rating Scale } \\
\text { (average) }\end{array}$ & $\begin{array}{l}\text { Both groups improved soon after intervention and at } 1 \text { - } \\
\text { month follow-up, but not statically significant. Average } \\
\text { mean pain intensity for intervention (before 5.30; after:4.41; } \\
1 \text { month } 3.98 \text { ) and control (before } 5.24 \text {; after } 4.32 ; 1 \text { month } \\
4.31 \text { ). Worst pain intensity score improvements in interven- } \\
\text { tion (before } 6.68 \text {; after } 5.90 ; 1 \text { month } 5.18 \text { ) and control (be- } \\
\text { fore } 6.38 \text {; after } 5.49 ; 1 \text { month 5.35) (Jensen } 2016 \text { ). }\end{array}$ & $\begin{array}{l}20 \\
(1 \mathrm{RCT})\end{array}$ & $\begin{array}{l}\oplus \odot \odot \ominus \\
\text { VERY LOW } 1,2\end{array}$ \\
\hline $\begin{array}{l}\text { Reduction in fatigue } \\
\text { assessed with: FSS }\end{array}$ & $\begin{array}{l}\text { Improvements over time pre to post treatment in interven- } \\
\text { tion (Jensen 2016). }\end{array}$ & $\begin{array}{l}20 \\
(1 \mathrm{RCT})\end{array}$ & $\begin{array}{l}\oplus \odot \odot \odot \\
\text { VERY LOW } 1,2\end{array}$ \\
\hline $\begin{array}{l}\text { Reduction in pain in- } \\
\text { terference } \\
\text { assessed with: BPI }\end{array}$ & BPI score improvement in both groups (Jensen 2016). & $\begin{array}{l}20 \\
(1 \mathrm{RCT})\end{array}$ & $\begin{array}{l}\oplus \odot \ominus \ominus \\
\text { VERY LOW } 1,2\end{array}$ \\
\hline
\end{tabular}

BPI: Brief Pain Inventory;FSS: Fatigue Severity Scale

\section{GRADE Working Group grades of evidence}

High certainty: We are very confident that the true effect lies close to that of the estimate of the effect

Moderate certainty: We are moderately confident in the effect estimate: The true effect is likely to be close to the estimate of the ef-

fect, but there is a possibility that it is substantially different

Low certainty: Our confidence in the effect estimate is limited: The true effect may be substantially different from the estimate of the effect

Very low certainty: We have very little confidence in the effect estimate: The true effect is likely to be substantially different from the estimate of effect

1 Downgraded two levels due to high risk for bias (unclear allocation concealment and no blinding of outcome assessors)

2 Downgraded two levels due to high risk for imprecision (singular study of small sample size)

\section{Summary of findings 8. Reflexology compared to Sham for Chronic Pain in Multiple Sclerosis (MS)}

\section{Reflexology compared to sham for chronic pain in MS}

Patient or population: chronic pain in MS

Setting: MS clinics, MS society

Intervention: reflexology

Comparison: sham

\begin{tabular}{llll}
\hline Outcomes & Impact & № of participants & $\begin{array}{l}\text { Certainty of the } \\
\text { (studies) }\end{array}$
\end{tabular}




\begin{tabular}{|c|c|c|c|}
\hline & & & (GRADE) \\
\hline $\begin{array}{l}\text { Reduction in pain } \\
\text { assessed with: VAS, } \\
\text { MPQ }\end{array}$ & $\begin{array}{l}\text { Compared to baseline; significant decrease in median pain VAS } \\
\text { in both reflexology ( } 50 \% \text { decrease at week 10) and sham ( } 50 \% \\
\text { decrease at week 10) (Hughes 2009). Significant reduction in } \\
\text { BPI scores in both groups, reflex group but no significant differ- } \\
\text { ences between groups. (Hughes 2009). } \\
\text { There were changes in mean pain VAS in both reflexology (pre- } \\
\text { test 5.72, post-test 3.16, } 2 \text { months } 4.64 \text { ) and control (pre-test } \\
5.88 \text {, post-test 5.60, } 2 \text { months 5.32) (Nazari 2016). }\end{array}$ & $\begin{array}{l}110 \\
(2 \mathrm{RCTS})\end{array}$ & $\begin{array}{l}\oplus \odot \odot \odot \\
\text { VERY LOW } 1,2\end{array}$ \\
\hline $\begin{array}{l}\text { Reduction in dis- } \\
\text { ability } \\
\text { assessed with: BI, } \\
\text { RMDQ }\end{array}$ & $\begin{array}{l}\text { Both the intervention and sham groups showed a significant } \\
\text { decrease in RMDQ by the end of the treatment period.BI scores } \\
\text { in both groups remained relatively stable throughout the dura- } \\
\text { tion of the trial in both groups (Hughes 2009). }\end{array}$ & $\begin{array}{l}71 \\
(1 \mathrm{RCT})\end{array}$ & $\begin{array}{l}\oplus \odot \odot \odot \\
\text { VERY LOW } 1,2\end{array}$ \\
\hline $\begin{array}{l}\text { Improvement in } \\
\text { Quality of Life } \\
\text { assessed with: } \\
\text { MSIS-29 }\end{array}$ & $\begin{array}{l}\text { MSIS- } 29 \text { psychological sub scale improved in both intervention } \\
\text { and sham by week } 10 . \\
\text { Physical sub scale significant decrease in both intervention } \\
\text { and sham, however this reduction was greater in the treatment } \\
\text { group by week } 10 \text { (Hughes 2009). }\end{array}$ & $\begin{array}{l}71 \\
(1 \mathrm{RCT})\end{array}$ & $\begin{array}{l}\oplus \odot \odot \odot \\
\text { VERY LOW } 1,2\end{array}$ \\
\hline $\begin{array}{l}\text { Reduction in Fa- } \\
\text { tigue } \\
\text { assessed with: } \\
\text { MFIS, FSS }\end{array}$ & $\begin{array}{l}\text { MFIS physical sub scale score significantly improved in both } \\
\text { sham and treatment by week } 10 . \\
\text { Significant reduction MFIS cognitive sub scale score in both } \\
\text { sham and treatment by week } 10 . \\
\text { Significant reduction in MFIS psychological sub scale in both } \\
\text { sham and treatment by the end of the treatment period. } \\
\text { Both sham and treatment demonstrated a significant reduction } \\
\text { in fatigue by week } 10 \text { (Hughes 2009). }\end{array}$ & $\begin{array}{l}71 \\
(1 \mathrm{RCT})\end{array}$ & $\begin{array}{l}\oplus \odot \Theta \odot \\
\text { VERY LOW } 1,2\end{array}$ \\
\hline $\begin{array}{l}\text { Reduction in de- } \\
\text { pression } \\
\text { assessed with: BDI } \\
\text {-II }\end{array}$ & $\begin{array}{l}\text { Both sham and treatment groups showed a significant reduc- } \\
\text { tion in values by week } 10 \text { (Hughes 2009). }\end{array}$ & $\begin{array}{l}71 \\
(1 \mathrm{RCT})\end{array}$ & $\begin{array}{l}\oplus \odot \odot \odot \\
\text { VERY LOW } 1,2\end{array}$ \\
\hline $\begin{array}{l}\text { Reduction in } \\
\text { Spasms } \\
\text { assessed with: VAS } \\
\text { for spasm }\end{array}$ & $\begin{array}{l}\text { Both sham and treatment demonstrated a statistically signif- } \\
\text { icant decrease in spasm by the end of the treatment (Hughes } \\
\text { 2009).. }\end{array}$ & $\begin{array}{l}71 \\
(1 \mathrm{RCT})\end{array}$ & $\begin{array}{l}\oplus \odot \odot \odot \\
\text { VERY LOW } 1,2\end{array}$ \\
\hline
\end{tabular}

BDI: Beck Depression Inventory; BI: Barthel Index; FSS: Fatigue Severity ScLE; MFIS: Modified Fatigue Impact Scale; MSIS-29: Multiple Sclerosis Impact Scale-29; VAS; Visual Analogue Scale

\section{GRADE Working Group grades of evidence}

High certainty: We are very confident that the true effect lies close to that of the estimate of the effect

Moderate certainty: We are moderately confident in the effect estimate: The true effect is likely to be close to the estimate of the effect, but there is a possibility that it is substantially different

Low certainty: Our confidence in the effect estimate is limited: The true effect may be substantially different from the estimate of the effect

Very low certainty: We have very little confidence in the effect estimate: The true effect is likely to be substantially different from the estimate of effect

1 Downgraded two levels due to high risk of attrition bias and unclear risk of bias in blinding and allocation concealment

2 Downgraded two levels due to high risk for imprecision (small sample size) 


\section{B A C K G R O U N D}

All technical terms used are listed in a Glossary (Appendix 1).

Multiple sclerosis (MS) is a chronic neurological disease characterised by unpredictable patchy inflammation, scarring and demyelination of the central nervous system (CNS). Despite advances in MS management, it remains one of the most common causes of neurological disability in young adults, affecting 1.3 million people worldwide (WHO 2008) and approximately 20,000 persons in Australia (MS Society 2011). The median estimated incidence of MS globally is 2.5 per 100,000 (range of 1.1 to 4) (WHO 2008), while the prevalence rate is about 30 per 100,000 population (range 5 to 80 ) (Trisolini 2010; WHO 2008). It is more common in women (3:1 ratio) and patterns of MS presentation can vary significantly between individuals (Compston 1998; Detels 1978; Hammond 1988). The exact aetiology of MS is still unclear, but it is associated with an abnormal immune response within the CNS, possibly due to an infectious agent (Kurtzke 1983). Genetic risk has also been shown in recent literature, indicating an association between HLA-DRB1 and HLA-DR4 genes and MS susceptibility (O'Gormann 2012). MS is associated with long-term physical, cognitive and behavioural disabilities, restrictions in participation, medical complications, and symptoms including pain (Khan 2007b; Khan 2013).

\section{Description of the condition}

According to the International Association of the Study of Pain (IASP), chronic pain is defined as "pain presenting continuously or intermittently for at least three months past the normal time of healing" (Merskey 1994). Chronic pain impacts on activities of daily living, relationships, and social roles (Archibald 1994; Ehde 2003; Khan 2007a; Svendson 2003; Warnell 1991), interferes with work (Archibald 1994), and has been associated with increased psychological impairment, such as depression (Ehde 2003). Many psychosocial factors influence adjustment to chronic pain, including pain-related beliefs, coping behaviours, family members' responses to pain behaviours (Fordyce 1973), psychological distress, and pain-related disability (Jensen 1999). Chronic pain is associated with poorer general health, increased fatigue, and higher rates of healthcare utilisation (Blyth 2003; Ehde 2003; Ma 2014; Sullivan 1992; Vickrey 1995;). It is a significant health problem, impacting working-age populations and causing social disadvantage (Blyth 2003; Shahrbanian 2013), with an estimated cost of approximately $\$ 34$ billion per annum in Australia alone (Blyth 2001).

In persons with MS (pwMS), symptoms such as headache and neuropathic extremity pain, back pain, painful spasms and Lhermitte's phenomenon are common and trigeminal neuropathic pain is least common. However, there is no confirmed prevalence and/or incidence rate of these symptoms in the literature.

Pain can be a significant problem for a substantial proportion of pwMS (Ehde 2005; Khan 2007a). It is estimated that $42 \%$ to 90\% pwMS experience pain (Clifford 1984; Heckman-Stone 2001; Moulin 1988; Stenager 1991; Vermote 1986), and occurs at all stages of the disease. MS-related pain can cause both acute and chronic symptoms. It is associated with active inflammation from the MS process itself (central neuropathic pain such as trigeminal neuropathic pain) and from MS-related complications (tonic spasms, headaches and musculoskeletal problems such as posture and gait anomalies) (Khan 2011). Pain is reported as one of the most severe symptoms in 8\% to 32\% of pwMS (Albert 1969; Shibasaki 1974; Stenager 1991) and it often co-exists as a mix of acute, paroxysmal and chronic pain in the same or various parts of the body (Foley 2013; Von Korff 1992).

Based on the underlying pathophysiological mechanism, MSrelated pain can be classified into 5 categories (Truini 2013).

- Neuropathic pain, defined by the IASP (Merskey 1994) as pain arising directly from a lesion or disease affecting the somatosensory system (Treede 2008), which can consist of persistent extremity pain and dysaesthesia, trigeminal neuropathic pain, and Lhermitte's phenomenon (defined as a transient sensation related to neck movements felt in the back of the neck, lower back and other parts of the body) (Al-Araji 2005).

- Nociceptive pain, either inflammatory or non-inflammatory, includes musculoskeletal and low back pain that may be posture-related, optic neuritis (Truini 2013), headaches and treatment-induced pain.

- Psychogenic pain is difficult to define and refers to somatoform pain associated with psychiatric conditions such as depression and anxiety or pain behaviours that have evolved in patients with chronic refractory pain.

- Idiopathic pain includes conditions which are either poorly understood or controversial such as fibromyalgia, interstitial cystitis and atypical facial pain.

- Mixed pain encompasses a heterogeneous group of pain with different pathophysiological mechanisms caused by MS (such as painful tonic spasms which may involve unilateral, bilateral or stereotyped involuntary muscle spasms and spasticity pain).

\section{Description of the intervention}

In general, pain in MS is treated with pharmacological agents (Cutter 2000; Rog 2005; Rossi 2009; Shakespeare 2003) and nonpharmacological modalities, or a combination of both (Saifuddin 2014). For the purpose of this review, non-pharmacological therapies or interventions refer to treatments and management strategies that do not involve the use of medications or surgery (Amatya 2013; Boldt 2011). A wide range of non-pharmacological interventions have been trialled for the management of pain in pwMS. Previous studies (Heckman-Stone 2001; Khan 2007a; Khan 2013) have found that MS patients in the community setting frequently use a wide variety of non-pharmacological techniques, which include passive strategies such as transcutaneous electrical nerve stimulation (TENS), heat and/or cold therapy, supportive braces, alternative therapies; and active strategies such as exercise, biofeedback, relaxation, distraction, and psychosocial interventions (Khan 2007a; Khan 2013). The availability of a variety of therapeutic techniques was postulated to empower patients with greater control of their pain management and possibly allow more optimal adaptation to a progressive condition.

\section{How the intervention might work}

The underlying mechanisms of pain in MS are unclear and have been linked with the differentiation and disinhibition of central and peripheral pathways, CNS lesions causing hyperexcitability, and increased neuronal (nerve cell) activity at the site of the lesion in the spinal cord (Beric 1998; Boivie 1999; Hans 2003; Lalkhen 2012). Chronic pain may develop and evolve as a maladaptive response involving neuronal pathways that are affected by internal 
and environmental influences in a complex interplay that is then perceived in a highly subjective fashion by each individual. It can arise both centrally and peripherally, and may be triggered by either a noxious or a non-noxious stimulus or can also occur spontaneously in the absence of any definable trigger (Boivie 1999; Jensen 1994; Jensen 1999;). Due to this heterogeneity of chronic pain aetiology amongst pwMS, modalities that act at different sites along the pain processing pathway may have variable degrees of effectiveness (Khan 2011; Lalkhen 2012).

Although the exact role of physiological deconditioning in nociceptive input or perceived pain is not well defined, it is clear that improvement in overall physical function is linked with improvement in psychosocial function and mood (Simmonds 1996), which in turn influences levels of pain. There is evidence that motor control and proprioceptive efficiency are altered, balance is compromised, and reaction times are slower in persons with pain (Harding 1998). TENS and acupuncture attempt to modulate pain from the periphery, whilst dorsal column stimulation intercepts the nociceptive signal at the level of the spinal cord. Cognitive behavioural therapy and other psychotherapies, on the other hand, utilise strategies that modify perception and cognition to enact a positive change in behaviour and mood.

\section{Why it is important to do this review}

Pain is prevalent in pwMS and tends to increase over time, due to the disease process itself and from MS-related complications, and is associated with a great interference with pwMS' daily life activities (Khan 2013). Several studies have demonstrated that those with higher pain grades reported more disability and healthcare visits, and lower quality of life (QoL) (Khan 2007a). Non-pharmacological therapies are widely used, both in hospital and ambulatory/mobility settings, to improve pain control, coping ability, daily function and QoL in pwMS. Chronic pain is found to be amenable to multidisciplinary rehabilitation management (Finlayson 2011; Karjalainen 2003; Khan 2007b; Kraft 2005; Saifuddin 2014). Psychological interventions have shown potential beneficial impact on pwMS, including the management of symptoms such as pain and fatigue (Thomas 2006). Further, TENS is commonly trialled for chronic low back pain in pwMS and hypoalgesic effects (Al Smadi 2003). Similarly, anodal transcranial Direct Current Stimulation (tDCS) has demonstrated effectiveness in reducing central chronic pain in the MS population (Mori 2010). To our knowledge, there is only one published systematic review on non-pharmacological management in pwMS (Jawahar 2014), which excluded non-spastic and non-trigeminal pain. This review identified the main categories of non-pharmacological interventions, which included education, electrical and physical therapy. The reviewers found that low-frequency TENS had the greatest reduction in pain scores (Jawahar 2014). This systematic review did have several limitations, including inclusion of nonrandomised clinical trials and pilot studies, and exclusion of various non-pharmacological interventions, such acupuncture, massage therapy, thermotherapy, electrical therapy such as transmagnetic stimulation (TMS) and tDCS. An updated systematic evaluation of the existing evidence is therefore needed to determine the effectiveness and safety of all non-pharmacological modalities to provide treating clinicians clear guidance for clinical decisionmaking for appropriate pain management in pwMS.

\section{O B JECTIVES}

This review aimed to investigate the effectiveness and safety of non-pharmacological therapies for the management of chronic pain in persons with multiple sclerosis (pwMS).

Specific questions to be addressed by this review include the following.

- Are non-pharmacological interventions (unidisciplinary or multidisciplinary, or both, rehabilitation interventions) effective in reducing chronic pain in pwMS?

- What type of non-pharmacological interventions (unidisciplinary or multidisciplinary, or both, rehabilitation interventions) are effective (least and most effective) and in what setting, in reducing chronic pain in pwMS?

\section{METHODS}

\section{Criteria for considering studies for this review}

\section{Types of studies}

All published randomised controlled trials (RCTs), including crossover studies that compared non-pharmacological interventions with no treatment, sham and usual care, for managing chronic pain in pwMS were included. Clinical controlled trials (CCTs) were eligible for inclusion, but none were identified. We included only trials with a full journal publication, with a minimum treatment period of two weeks or more, with greater attention given to studies with a duration of eight weeks or greater. We excluded studies of experimental pain, observational studies, case reports, and clinical observations.

\section{Types of participants}

We included trials if the study population had a confirmed diagnosis of MS based on standard criteria (McDonald 2001) and participants were aged 18 years and older with chronic pain. All studies with participants with 'chronic pain' or participants suffering from pain longer than three months were included, irrespective of the use of varying definitions for chronicity of pain. We included studies that recruited participants with the minimum levels of pain on visual analogue scale (VAS) of $3 / 10$. Studies including participants with other diagnoses were excluded unless individual data for the pwMS could be obtained either from the published results or through contact with authors.

\section{Types of interventions}

All non-pharmacological interventions to manage chronic pain in pwMS delivered in any settings (inpatient, outpatient, community, or home-based) were included.

- Unidisciplinary: physiotherapy, occupational therapy, and individual treatment modalities, thermotherapy such as heat and cold application, psychological and behavioural therapies including cognitive behavioural therapy and hypnosis, relaxation training, yoga, massage, chiropractic manipulation, acupuncture, other alternative and complementary therapies, TMS, TENS, tDCS, dorsal root entry zone (DREZ) lesioning and others.

- Multidisciplinary rehabilitation programmes, defined as any co-ordinated therapy programme delivered by two or more disciplines (occupational therapy, physiotherapy, exercise 
physiology, orthotics, other allied health and nursing) in conjunction with medical input (neurologist or rehabilitation medicine physician) that aims to achieve patient-centred goals related to reducing chronic pain.

Control interventions that are likely used for comparison with the above mentioned interventions include no treatment, sham and usual care.

\section{Types of outcome measures}

Diverse outcomes were expected, given the varied presentations of pain-related problems and goals of treatment related to pain severity in MS.

\section{Primary outcomes}

The primary outcome determined whether the intervention produces reduction in pain measured by validated measurers, such as a visual analogue scale (VAS) or numerical rating scale (NRS) (Jensen 2001), Likert scale such as the Patient's Global Impression of Change (PGIC, Hurst 2004), or Clinical Global Impression of Change (CGIC, Zaider 2003), or specific pain scales such as the McGill Pain Questionnaire (MPQ, Melzack 1975), Short Form McGill Pain Questionnaire (SFMPQ, Melzack 1987), or Brief Pain Inventory (BPI, Cleeland 1989), and others (subjective or objective). We used the Initiative on Methods, Measurement, and Pain Assessment in Clinical Trials (IMMPACT) (Dworkin 2008) criteria, defined as:

- at least $30 \%$ pain relief over baseline (moderate);

- at least $50 \%$ pain relief over baseline (substantial);

- much improved on Patient Global Impression of Change Scale (PGIC; moderate);

- very much improved on PGIC (substantial).

\section{Secondary outcomes}

Due to the multidimensional model of pain, we included secondary outcomes determining whether the change in pain by the intervention affects the other specific outcome(s) measured by validated tools, which included:

- other symptoms or impairments, such as spasticity, fatigue, e.g. Multiple Sclerosis Spasticity Scale (MSSS-88, Hobart 2006); Modified Ashworth Scale (MAS, Ansari 2009); Fatigue Impacts Scale (FIS, Fisk 1994); Modified Fatigue Impact Scale (MFIS,Larson 2013); Fatigue Severity Score (FSS,Krupp 1989);

- functional activity, e.g. Functional Independence Measure (FIM, Granger 1998); Barthel index (BI, Mahoney 1965); Rowland Morris Disability Questionnaire (RMDQ, Stevens 2016);

- psychosocial outcomes, e.g. Beck Depression Inventory (BDI, Beck 1961); Depression, Stress and Anxiety Scale (DASS, Lovibond 1995); Hospital Anxiety Depression Scale (HADS, Snaith 2003); Patient Health Questionnaire 9 (PHQ-9, Kroenke 2001);

- restriction in participation/impact on carers, e.g. Caregiver Strain Index (CSI, Robinson 1983);

- vocational outcomes, e.g. Work Instability Scale (WIS, Gilworth 2003);

- quality of life, e.g. Multiple Sclerosis Quality of Life (MSQOL54, Vickrey 1995); Short Form Health Survey (SF-36, Ware 2000); Leeds Multiple Sclerosis Quality of Life (LMSQOL, Ensari 2016); Multiple Sclerosis Impact Scale (MSIS-29, Hobart 2001);
- withdrawals, due to lack of efficacy;

- outcomes that reflect utilisation of healthcare resources and associated cost (reported, where possible);

- participants experiencing any adverse effects;

- participants experiencing any serious adverse effects, which include any untoward medical occurrence or effect that results in death, is life-threatening, requires hospitalisation or prolongation of existing hospital stay, results in persistent or significant disability or incapacity, congenital anomaly or birth defect, that may jeopardise the person or may require intervention.

\section{Timing of outcome measures}

We divided outcome time points into short term (up to three months) and long term (greater than three months) from the start of the intervention.

\section{Search methods for identification of studies}

We considered articles in all languages with a view to translation, if necessary.

\section{Electronic searches}

The Information Specialist searched (up to 10 December 2017) the Trials Register of the Cochrane MS and Rare Diseases of the CNS Group, which, among other sources, contains trials from:

- Cochrane Central Register of Controlled Trials (CENTRAL) (2017, issue 12):

- MEDLINE (PubMed) (1966 to 10 December 2017);

- Embase (Embase.com) (1974 10 December 2017);

- Cumulative Index to Nursing and Allied Health Literature (CINAHL) (EBSCOhost) (1981 to 10 December 2017);

- Latin American and Caribbean Health Science Information Database (LILACS) (Bireme) (1982 to 10 December 2017);

- ClinicalTrials.gov (https://clinicaltrials.gov/); and

- World Health Organization (WHO) International Clinical Trials Registry Platform (http://apps.who.int/trialsearch/).

The keywords that were used to search for trials for this review are listed in Appendix 2.

Information on the Group's Trials Register and details of search strategies used to identify trials can be found in the 'Specialised Register' section within the Cochrane MS and Rare Diseases of the Central Nervous System Group's module.

In addition we searched the following databases:

- PsycINFO (1980 to 10 December 2017), (Appendix 3);

- Allied and Complementary Medicine Database (AMED) (1985 to 10 December 2017) (Appendix 4); and

- MANTIS/Ovid (for most recent data available) (Appendix 5).

\section{Searching other resources}

We conducted an expanded search to identify articles potentially missed through the database searches and articles from 'grey literature'. These were:

- related articles feature (via PubMed);

- ProQuest Dissertations and Theses; 
- Web of Science for citation of key authors;

- SIGLE (System for Information on Grey Literature in Europe); and

- contact authors and researchers active in this field.

\section{Data collection and analysis}

\section{Selection of studies}

Two review authors (BA, JY) independently screened and shortlisted all abstracts and titles of studies identified by the search strategy for appropriateness based on the selection criteria. The same review authors (BA, JY) independently reviewed the abstract of each study from the short list of potentially appropriate studies for inclusion or exclusion. The full text of the article was obtained to determine if the study met the inclusion/exclusion criteria. Articles assessed in full text that did not meet the inclusion criteria were listed in the Characteristics of excluded studies with the reasons for exclusion. If no consensus was met about the possible inclusion/exclusion of any individual study, a final consensus decision was made by discussion with the third author (FK). Review authors were not masked to the name(s) of the author(s), institution(s) or publication source at any level of the review. Further information was sought about the method of randomisation and other methodological issues, if required. We excluded studies with fatal flaws (for instance, withdrawals by more than $40 \%$ of the participants, or nearly total non-adherence to the protocol, or very poor or non-adjusted comparability in the baseline criteria).

\section{Data extraction and management}

Two review authors (BA, JY) independently extracted the data from the included trials using a standardised form and entered the data into the RevMan software (Review Manager 2014), which included:

- year of publication, year the study was undertaken, and geographical location of the study;

- number of participants included, their age, gender, and type of MS;

- information about the type of pain (neuropathic/nociceptive) that is targeted by the study intervention;

- type of study intervention and treatment duration;

- information about the control intervention(s);

- duration of the study recruitment and follow-up time;

- information about adverse events;

- information about withdrawals;

- information whether the study was specifically designed to measure pain in MS;

- information about study quality; and

- measures of treatment effect (outcome measures).

A final check was made by a third review author (FK). To summarise all data on reduction in pain, we used the benchmarks of the IMMPACT recommendations for the evaluation of reduction in pain (Dworkin 2008). We summarised all studies that met the inclusion criteria in the Characteristics of included studies table.

\section{Assessment of risk of bias in included studies}

Two review authors (BA, JY) independently assessed the methodological quality of the included studies using the 'Risk of bias' tool outlined in the Cochrane Handbook for Systematic Reviews of Interventions (Higgins 2011). We assessed the following for each study:

- Random sequence generation (selection bias): we assessed the method used to generate the allocation sequence as: low risk of bias (any truly random process, random number table, computer random generator) and unclear risk of bias (when the method is not clearly stated). We excluded studies with a nonrandom process.

- Allocation concealment (selection bias): we assessed method used to conceal the allocation to interventions prior to assignment determines whether the intervention allocation could have been foreseen in advance, during recruitment, or changed after assignment. We assessed methods as low risk of bias (telephone or central randomisation; consecutively numbered, sealed, opaque envelopes) or unclear risk of bias (when method is not clearly stated).

- Blinding of participants and personnel (performance bias): we assessed the methods used to blind study participants, personnel. We assessed methods as low risk of bias (study states it was blinded and described the method used to achieve the blinding) and unclear risk of bias (study stated it was blinded but did not provide adequate description of how this was achieved).

- Blinding of outcome assessment (detection bias): we assessed the methods used to blind the allocated interventions by outcome assessors. We assessed methods as low risk of bias (study states blinding of outcome assessments ensured) or unclear risk of bias (when method is not clearly stated) and high risk (no blinding of outcome assessment)

- Incomplete outcome data (attrition bias): we assessed the methods used to deal with incomplete data as low risk of bias (fewer than $10 \%$ of participants did not complete the study or used 'baseline observation carried forward' analysis or both), unclear risk of bias (used 'last observation carried forward' analysis) or high risk of bias (used 'completer' analysis).

- Selective reporting (reporting bias): we assessed the methods used to report outcomes and selective reporting. We assessed methods as low risk of bias (all of the study's prespecified outcomes and protocol is available), unclear risk (insufficient information) or high risk (not all of the study's prespecified outcomes is reported).

- Other bias: we assessed other bias as low risk (free of other sources of bias), unclear risk (insufficient information) or high risk (potential source of bias).

Any disagreements or lack of consensus was resolved by the third review author (FK).

\section{Measures of treatment effect}

All quantitative data were entered and analysed in the RevMan software (Review Manager 2014). For each outcome of interest, summary estimates of treatment effect (with 95\% confidence intervals $(\mathrm{Cls})$ ) for each comparison were calculated. Where possible, risk ratios (RRs) with $95 \% \mathrm{Cls}$ for dichotomous data and difference in means or standardised difference in means (SMD) with $95 \% \mathrm{Cls}$ for continuous data were calculated. The results of individual studies were discussed and presented in table and graphical format, where data aggregation was not possible. 


\section{Unit of analysis issues}

The appropriate unit of analysis involved the type, intensity, and setting of non-pharmacological interventions. A qualitative analysis using the GRADE approach for existing evidence was attempted in any event (Higgins 2011). Trials with multiple observations for the same outcome were assessed according to randomisation and types of interventions, and separate analyses based on different periods were performed. Studies with parallel groups were included, but only data from the first phase of crossover trials were included, due to the potential carry-over effects in the second phase.

\section{Dealing with missing data}

Insufficient data that were not available were reported but not included in the final analysis. We assumed the data were missing at random and only available data were analysed.

\section{Assessment of heterogeneity}

We conducted statistically analysis, as described in the Cochrane Handbook for Systematic Reviews of Interventions (Higgins 2011).

\section{Assessment of reporting biases}

Publication bias was minimised by performing comprehensive searches of multiple databases (Egger 1998). Where data were not reported in full for certain outcomes, we contacted the trial authors for the full data set or the reason for not publishing the data. Where sufficient studies (at least 10) were identified, we assessed potential biases of reporting using funnel plots and visual inspection for asymmetry according to the approach outlined in the Cochrane Handbook for Systematic Reviews of Interventions (Higgins 2011).

\section{Data synthesis}

A meta-analysis was not possible due to methodological, clinical and statistically heterogeneity of included studies. We would have pooled results from clinically similar studies for the meta-analysis, if sufficient studies were available.

\section{Subgroup analysis and investigation of heterogeneity}

Treatment effects in subgroups of trials were analysed and compared. With data that were available, we performed subgroup analysis for the following:

- sex (male/female);

- type of MS (relapsing remitting, progressive);

- Expanded Disability Status Scale (EDSS) $(<6,>6)$;

- duration of follow-up of the participants (three months; $>$ three months);
- type of non-pharmacological intervention (unidisciplinary and/ or multidisciplinary rehabilitation); and

- settings (i.e. inpatient, ambulatory care, community).

\section{Sensitivity analysis}

We were unable to perform sensitivity analysis because the findings from included studies evidence were too small to allow reliable analysis. Further, we were not able to pool results from chronic pain of different central origins in the primary analyses, due to lack of data.

\section{'Summary of findings' table}

We presented the main results of the review in 'Summary of findings' (SoF) tables, according to recommendations described in Chapter 11 of the Cochrane Handbook for Systematic Reviews of Interventions (version 5.1.0). We included an overall grading of the evidence for the following patient-important outcomes:

- reduction in pain intensity;

- reduction in disability;

- improvement in quality of life;

- reduction in fatigue;

- reduction in depression and anxiety;

- reduction in pain interference, depression, fatigue;

- improvement in pain, self efficacy, patient activation, healthrelated quality of life, social role satisfaction, resilience,positive and negative affect.

We graded the quality of evidence for each outcome considering study limitations, indirectness, inconsistency, imprecision of effect estimates, and risk of reporting bias. According to the software GRADEpro 2008, we assigned four levels of quality of evidence: high, moderate, low, and very low.

\section{RE S U L T S}

\section{Description of studies}

See: Characteristics of included studies and Characteristics of excluded studies

\section{Results of the search}

Electronic and manual searches identified 558 references (MEDLINE $=361 ;$ Embase $=138 ; \mathrm{CINAHL}=21 ;$ Central $=9 ;$ CRD database $=4$; Handsearch $=7$; WHO portal $=4$; Cinicaltrials.gov $=14$ ). Of these 30 passed the first screening review and were selected for closer review. In total 10 articles fulfilled the inclusion criteria and were included. See Figure 1 for Study flow chart. 
Figure 1. Study flow diagram.

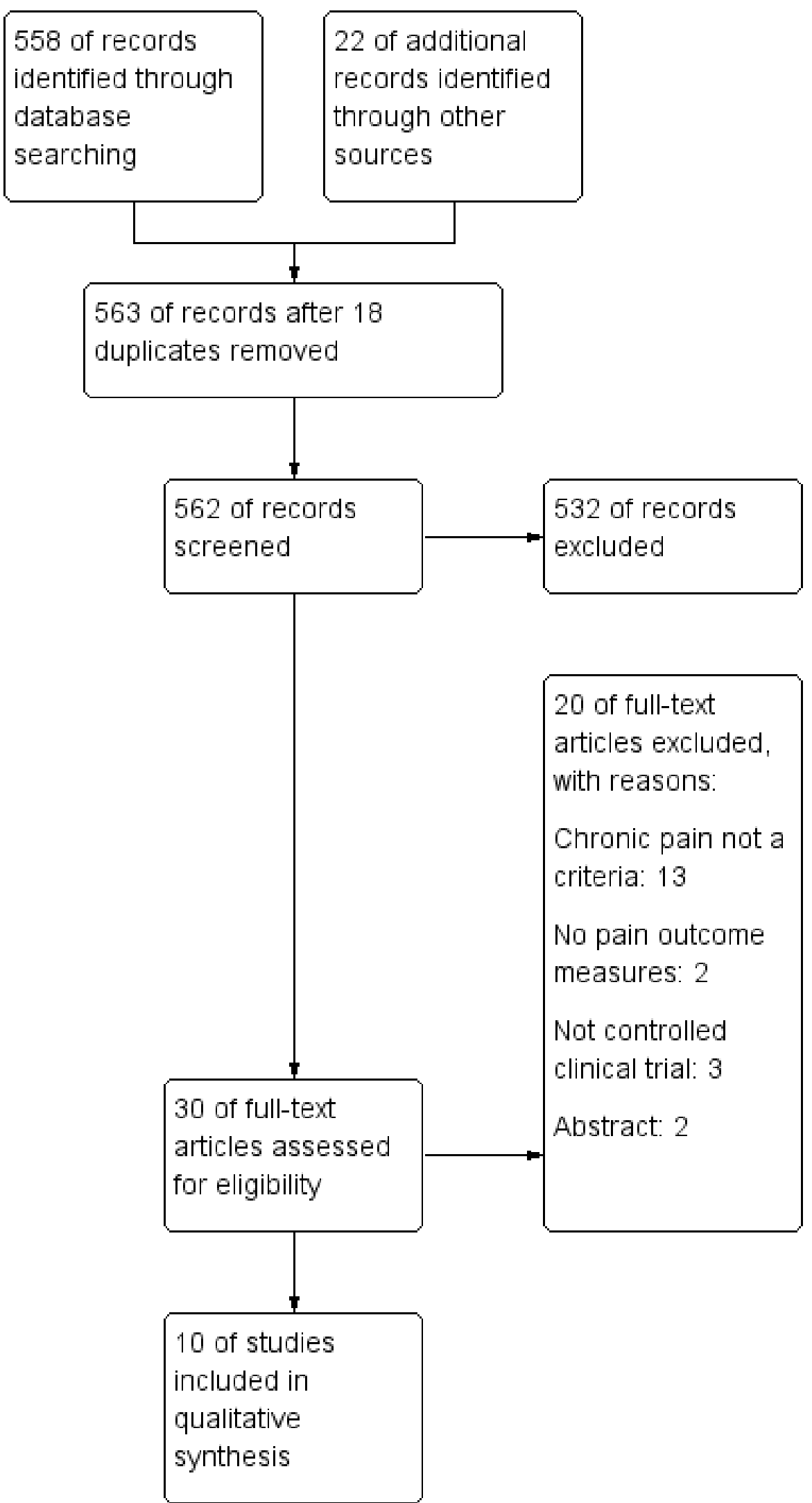




\section{Included studies}

Overall, 10 randomised controlled trials (RCTs) (Ayache 2016; Castro-Sanchez 2012; Ehde 2015; Hughes 2009; Jensen 2009; Jensen 2016; Mori 2010; Nazari 2016; Palm 2016; Warke 2006 (extension of Warke 2004)) involving 565 participants fulfilled the inclusion criteria for this review. Two studies were conducted in Northern Ireland (Hughes 2009; Warke 2006); three studies in the USA (Ehde 2015; Jensen 2009; Jensen 2016); two studies were from France (Ayache 2016; Palm 2016); and one study each from Spain (Castro-Sanchez 2012), Italy (Mori 2010) and Iran (Nazari 2016).The included studies evaluated various non-pharmacological interventions, which included:

- one study (Warke 2006) evaluated the effects of TENS, which used alternating currents by cutaneous electrodes positioned near the painful area;

- two studies (Ayache 2016; Mori 2010) investigated the effects of tDCS, which used a low current directly delivered to the brain for neuromodulation;

- two studies (Hughes 2009; Nazari 2016) investigated the effects of reflexology, which involves the massaging of the feet which corresponds to different parts of the body;

- one study (Castro-Sanchez 2012) evaluated hydrotherapy;

- three studies (Ehde 2015; Jensen 2009; Jensen 2016) evaluated psychotherapy, which used a telephone-based self-management educational program, self-hypnosis and neurofeedback;
- one study (Palm 2016) evaluated tRNS, which used a form of neuromodulation through rapidly changing current frequencies.

\section{Excluded studies}

Detailed descriptions of excluded studies with reason for exclusion is provided in Characteristics of excluded studies. Overall, 20 studies were excluded (Anninos 2016; Backus 2016; Barlow 2009; Catena 2014; Doulatabad 2012; Hasanpour-Dehkordi 2015; Hasanpour-Dehkordi 2016; Jensen 2007; Jensen 2011; Marinelli 2015; Mathiowetz 2005; McGuire 2015; Negahban 2013; Oken 2004; Pilutti 2013; Pozzilli 2002; Seada 2013; Smedal 2011; Storr 2006; Van der Linden 2013). Reasons for exclusion included: 13 studies did not define chronic pain as a criteria (Doulatabad 2012; Hasanpour-Dehkordi 2015; Hasanpour-Dehkordi 2016; Marinelli 2015; Mathiowetz 2005; McGuire 2015; Negahban 2013; Oken 2004; Pilutti 2013; Pozzilli 2002; Smedal 2011; Storr 2006; Van der Linden 2013), two were abstracts only (Catena 2014; Jensen 2007), three were not clinical controlled trials (Backus 2016; Jensen 2011; Seada 2013), and two trials did not have pain as an outcome (Anninos 2016; Barlow 2009).

\section{Risk of bias in included studies}

For a summary, please see Risk of bias' tables in the Characteristics of included studies and Figure 2 and Figure 3. 
Figure 2. 'Risk of bias' summary: review authors' judgements about each risk of bias item for each included study.

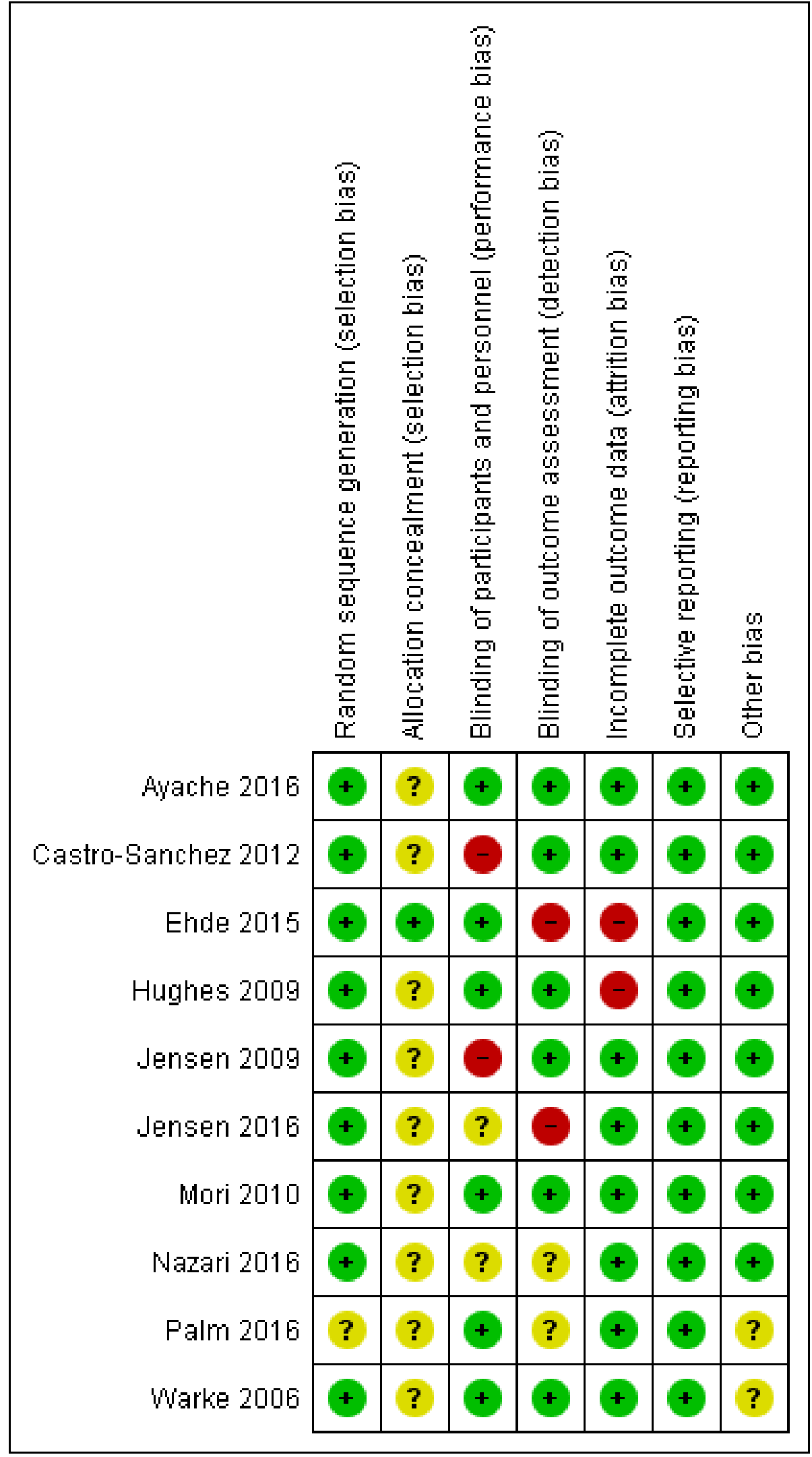


Figure 3. 'Risk of bias' graph: review authors' judgements about each risk of bias item presented as percentages across all included studies.

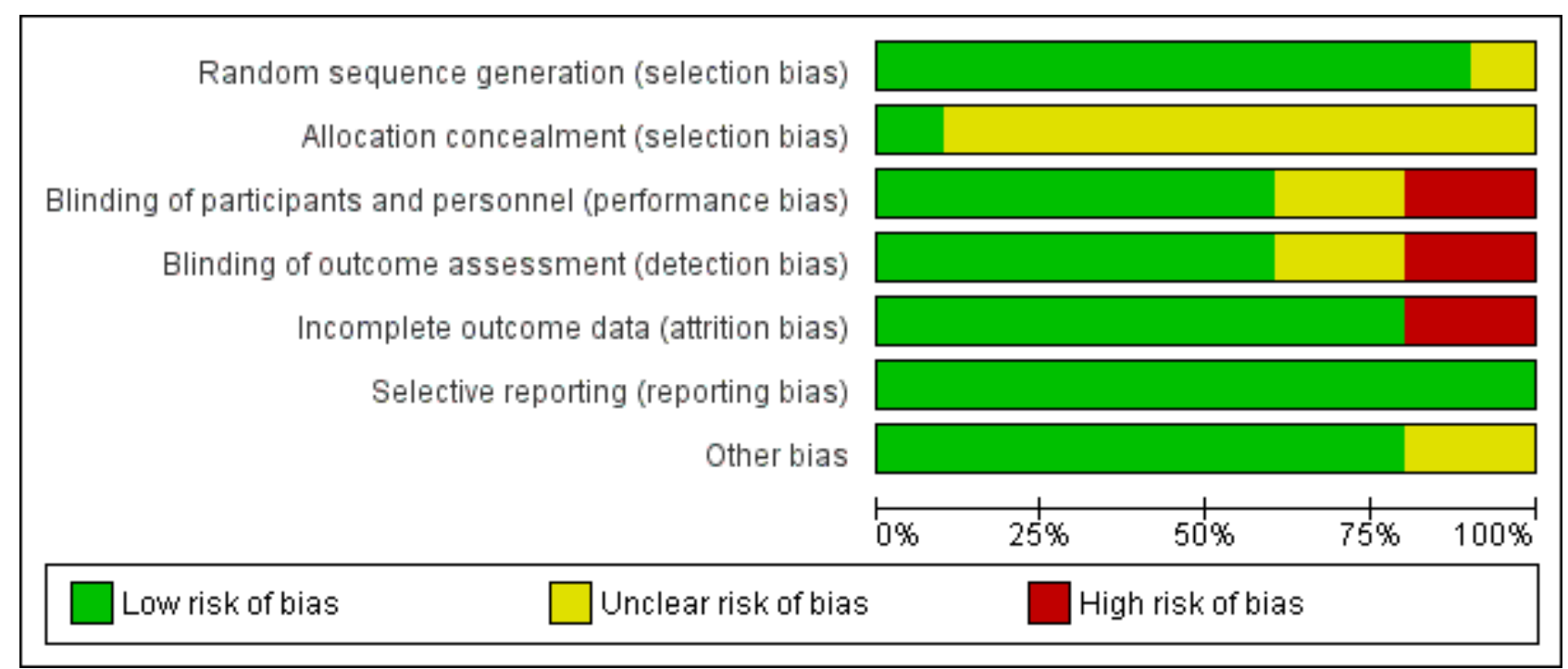

\section{Allocation}

\section{Random sequence generation}

Nine studies were considered to have a low risk of bias for this domain (Ayache 2016; Castro-Sanchez 2012; Ehde 2015; Hughes 2009; Jensen 2009; Jensen 2016; Mori 2010; Nazari 2016; Warke 2006). Palm 2016 was considered to have an unclear risk of bias for this domain as randomisation not discussed.

\section{Allocation concealment}

One study (Ehde 2015) was considered to have a low risk of bias for allocation concealment as the allocation sequence was concealed from the research assistants who enrolled participants via a limited access database program. The other nine studies were considered to have an unclear risk of bias for allocation concealment (Ayache 2016; Castro-Sanchez 2012; Hughes 2009; Jensen 2009; Jensen 2016; Mori 2010; Nazari 2016; Palm 2016; Warke 2006).

\section{Blinding}

\section{Blinding of participants and personnel (performance bias)}

Blinding of participants for performance bias was assessed as high risk in two studies (Castro-Sanchez 2012; Jensen 2009), as the study could not guarantee the study was blinded and no blinding reported, respectively. Two studies had an unclear risk of bias (Jensen 2016; Nazari 2016). The remaining six studies had a low risk of bias (Ayache 2016; Ehde 2015; Hughes 2009; Mori 2010; Palm 2016; Warke 2006).

\section{Blinding of participants and personnel (detection bias)}

Two studies were assessed as unclear risk for blinding of outcome assessment as blinding was not described (Nazari 2016; Palm 2016) and two studies were assessed as high risk (Ehde 2015; Jensen 2016).

\section{Incomplete outcome data}

All studies provided information on participant withdrawals and loss to follow-up. Two studies ( Ehde 2015; Hughes 2009) reported loss of participants to follow-up and were assessed as high risk; the remaining studies were considered to be at low risk of bas.

\section{Selective reporting}

All included studies assessed pre-specified primary and secondary outcomes and were assessed as 'low' risk.

\section{Other potential sources of bias}

Two studies (Palm 2016; Warke 2006) were assessed as unclear risk as funding was received but it was unclear if it had an impact on results.

\section{Effects of interventions}

See: Summary of findings for the main comparison Transcutaneous Electrical Nerve Stimulation (TENS) compared to Sham for Chronic Back Pain in Multiple Sclerosis (MS); Summary of findings $2 \mathrm{Ai}$ Chi Exercises compared to Sham for Chronic Musculoskeletal pain in Multiple Sclerosis (MS); Summary of findings 3 Transcranial Direct Current Stimulation (tDCS) compared to Sham for Chronic Neuropathic Pain in Multiple Sclerosis (MS); Summary of findings 4 Transcranial Random Noise Stimulation (tRNS) compared to Sham for Chronic Neuropathic Pain in Multiple Sclerosis (MS); Summary of findings 5 TelephoneDelivered Education Group compared to Sham for Chronic pain in Multiple Sclerosis (MS); Summary of findings 6 Hypnosis compared to relaxation control for chronic pain in Multiple Sclerosis (MS); Summary of findings 7 Neurofeedback compared to relaxation control for chronic pain in Multiple Sclerosis (MS); Summary of findings $\mathbf{8}$ Reflexology compared to Sham for Chronic Pain in Multiple Sclerosis (MS)

As aforementioned, the included studies used a wide range of non-pharmacological interventions and used various assessments relating to pain measures. Key findings based on the interventions 
evaluated and summary of findings are described below and tabulated in 'Summary of Finding' tables. A meta-analysis was not possible and narrative descriptions of the findings are presented instead.

\section{Transcutaneous electrical nerve stimulation (TENS)}

One study (Warke 2006) evaluated the effects of TENS on chronic low back pain in persons with multiple sclerosis (pwMS). (Summary of findings for the main comparison)

In this study, 90 participants were randomised into three groups ( $N=30$ in each): low-frequency TENS, high-frequency TENS and placebo (sham). There was a decrease in low back pain scores overtime in all three groups in visual analogue scores (VAS), however, none reached statistical significance. Similarly, no statistically significant changes in the McGIll Pain Questionnaire (MPQ) was found in all three groups. All three groups showed improvement in patient-reported disability scores ( Roland Morris Disability Questionnaire (RMDQ)), however, it was not statistically significant.

\section{Hydrotherapy}

One RCT ( $N=73$ participants) (Castro-Sanchez 2012) evaluated the effectiveness of $\mathrm{Ai}$ Chi water-based exercise program compared to placebo. The participants in the intervention group received $\mathrm{Ai} C \mathrm{Chi}$ water exercises twice a week for 20 weeks. The authors reported significant reduction in pain VAS score in the treatment group immediately after treatment $(P=0.028)$, which was maintained up to 30 weeks $(P=0.047)$. There were no statistical significance changes in the control group at any time point. Similarly, compared to the control group, the treatment group showed a significant pain reduction at week 20 in MPQ and was maintained up to week $24(\mathrm{P}<0.021)$. There were significant decreases in disability (RMDQ) scores in both groups at week 20. The treatment group also showed a significant decrease in spasm VAS score at week 20 compared to the control group $(P=0.039)$. Both groups showed a significant reduction in the Multiple sclerosis Impact scale 29 (MSIS-29) psychological score at week 20. (Summary of findings 2)

\section{Transcranial direct stimulation (tDCS)}

Two studies (Ayache 2016; Mori 2010) evaluated the effectiveness of tDCS in pwMS. (Summary of findings 3 )

One RCT (Ayache 2016) ( $N=16$ ) randomised participants to either anodal tDCS $(\mathrm{N}=8)$ or sham $(\mathrm{N}=8)$ groups. The findings showed a statistically significant difference between before and after treatment for mean pain VAS scores in the treatment group $(P=0.024)$. There were no statistically significant changes in the sham group. Active stimulation resulted in significant improvement in pain ( Brief Pain Inventory (BPI) global score) $(P=0.02)$, but no significant effects on severity, or in the sham group. There were no significant differences observed through stimulation for both groups for functional and psychological outcomes for MFIS and HADS.

In another study (Mori 2010), participants ( $\mathrm{N}=19)$ were randomised to anodal tDCS $(\mathrm{N}=10)$ or sham $(\mathrm{N}=9)$ groups. There were statistically and clinical significant changes for pain VAS and MPQ scores in the anodal tDCS group compared to the control sham group $(P<0.05)$. The authors also reported statistically significant changes for the treatment effect over time in quality of life (QoL) for the Multiple Sclerosis Quality of Life-54 (MSQOL54) and the Short Form Mcgill Pain Questionnaire (SFMPQ). There were no statistically significant changes for other psychological outcomes ( Beck Depression Inventory (BDI) and VAS for anxiety) in both groups.

\section{Transcranial random noise stimulation (tRNS)}

One RCT ( $N=16$ participants) (Palm 2016) examined the effect of tRNS in comparison with the sham. The authors found no statistically significant changes for mean pain VAS score before and after treatment for both tRNS and sham groups. There was a significant change in BPI in the treatment group but not in the sham group. Further, there were no statistically significant changes for any psychological and functional outcomes ( Hospital Anxiety and Depression Scale HADS), Modified Fatigue Impact Scale (MFIS) scores) in both groups. (Summary of findings 4)

\section{Psychotherapy}

Three RCTs (Ehde 2015; Jensen 2009; Jensen 2016) evaluated different forms of psychotherapy. (Summary of findings 5, Summary of findings 6 and Summary of findings 7)

One RCT (Ehde 2015) ( $N=163$ participants) compared a telephonedelivered self-management program with the control group receiving telephone-delivered educational program. The authors reported that $>50 \%$ reduction in one or more symptoms (fatigue, pain interference and depression severity) was achieved in $58 \%$ of the intervention group and $46 \%$ of the control group. However, this was not statistically significant. There were no clinical significant changes in pain intensity after treatment and at follow-up in both intervention and control group. The authors reported statistically significant improvements in all secondary outcomes (fatigue, selfefficacy, pain interference quality of life) for both groups, which was maintained up to six- and 12-month follow-up.

Another RCT (Jensen 2009) evaluating the effectiveness of selfhypnosis on pain in pwMS, randomised $(\mathrm{N}=22)$ participants to selfhypnosis $(N=15)$ and progressive muscle relaxation $(N=7)$ groups. The authors found statistically and clinically significant changes pre- and post- treatment in the hypnosis group in reduction in daily pain intensity but not in the control group $(P<0.001)$. There was also statistically significant change pre- to post-treatment in the hypnosis group, but not in the progressive relaxation group for pain interference $(P<0.001)$.

Another RCT (Jensen 2016) randomised $(N=20)$ participants to the EEG biofeedback $(\mathrm{N}=10)$ group or relaxation control group $(\mathrm{N}=10)$. Both groups improved in pain scores soon after treatment and at one-month follow-up, however this was not statistically significant. There was a moderate to large improvement in the neurofeedback group after treatment (effect size, ES $=0.70$ ) and 1 month after follow-up (ES = 1.04), but effect size of improvement was much lower in the control group. There were improvements for other pain scores (BPI, worst pain intensity) and fatigue severity in the intervention group with moderate to large effect size.

\section{Reflexology}

Reflexology was evaluated in two studies (Hughes 2009; Nazari 2016). (Summary of findings 8 )

One RCT (Hughes 2009) ( $\mathrm{N}=71$ participants) compared reflexology with a control group with sham intervention. The authors found 
clinical and statistically significant reduction in pain VAS scores at 10 weeks compared to baseline in both groups $(P=0.0001)$, which was maintained up to 22 weeks. Both groups demonstrated significant reduction in MPQ pain rating index at week 10 . For $M P Q$ pain index there were no changes in the sham group, but a statistically significant change at week 10 for the reflexology group $(P<0.012)$. Both groups showed a significant reduction in disability score measured by RMDQ at 10 weeks. Further, both groups had a similar statistically significant decrease in VAS spasm score by the end of the treatment period. Both groups showed significant reductions in psychology and physical subscales of MSIS at week 10 . There was a significant reduction by week 10 in both groups in fatigue (MFIS, Fatigue Severity Scale (FSS) scores), with no significant differences between groups. There was a significant reduction in psychological outcomes (BDI scores) by week 10 in both groups. Functional improvements (measured by the Barthel Index (BI)) in both groups remained stable throughout treatment by week 10 .

Another RCT (Nazari 2016) ( $\mathrm{N}=75$ participants) randomised participants to either reflexology, relaxation or control groups. There were statistically and clinical significant differences in pain scores in the reflexology group $(P<0.001)$ and relaxation group $(P$ $=0.01)$ pre- and post-treatment, while no significant changes were found in the control group $(P=0.34)$.

\section{DISCUSSION}

\section{Summary of main results}

Overall, 10 RCTs with 565 participants fulfilled the inclusion criteria of this review, which evaluated various non-pharmacological interventions for the management of chronic pain in persons with multiple sclerosis (pwMS), which included: physical therapy ( $\mathrm{Ai}$ Chi water exercise), psychotherapy (telephone self-management, cognitive restructuring, neurofeedback and hypnosis), neuromodulatory techniques (transcranial direct stimulation (tDCS), transcranial random noise stimulation (tRNS)), reflexology and transcutaneous electrical nerve stimulation (TENS). The included trials were heterogeneous in terms of: type and intensity of interventions evaluated and outcome measures used. The study quality varied and formulating pooled evidence was limited due to high risk of bias, underpowered studies (small sample size) and lack of data on changes of pain outcomes in majority of the studies. Therefore, quantitative synthesis was not possible and a qualitative synthesis of 'best evidence ' was summarised.

The findings suggest that there is 'very low level' evidence for the following interventions.

- TENS in reducing lower back pain.

- Ai Chi water exercises in improving pain intensity which was maintained up to 30 weeks. There were also improvements in spasm, quality of life(QoL) and fatigue.

- tDCS in reduction in pain intensity and up to three weeks after treatment and improvement in QoL, but not in fatigue and anxiety and depression.

- tRNS in improving pain scores, depression or anxiety or fatigue.

- Telephone-delivered self-management program for the reduction of pain intensity, catastrophisation, self-efficacy, fatigue and QoL in chronic pain.
- EEG biofeedback for reduction in pain intensity and fatigue and pain interference.

- Reflexology in reducing pain intensity, disability, fatigue, psychological and physical impact and depression up to 22 weeks.

\section{Overall completeness and applicability of evidence}

Despite a comprehensive search of the literature, only 10 trials evaluating a wide variety of non-pharmacological treatments fulfilled the inclusion criteria. Due to the quality of the published studies, many aspects of non-pharmacological interventions for multiple sclerosis (MS) pain remain unproven. Further, there were only few studies (which were heterogeneous) that evaluated a given type of intervention, which did not permit pooling data for quantitative analyses. There are other non-pharmacological interventions (e.g. yoga, massage therapy and radial shock wave therapy) which have been used for pain relief in pwMS, however, studies evaluating these interventions did not fulfil the inclusion criteria for this review. Cost-effectiveness of the intervention and reporting of safety or adverse events for participants were not evaluated in any of the included trials. Ovwerall, the review identified many issues relating to the studies evaluating nonpharmacological interventions in chronic pain in MS; which could affect the overall completeness and applicability of evidence. The gaps in the evidence base for non-pharmacological management of chronic pain in pwMS include the following.

- Limited and/or lack of high-quality evidence for the effectiveness of non-pharmacological interventions.

- Complexity and different mechanisms related to chronic pain in MS.

- Broad range of non-pharmacological interventions used in different context and with scope.

- Difficulty of blinding and incorporation of a control or placebo (sham).

- Lack of use of Initiative on Methods, Measurement, and Pain Assessment in Clinical Trials (IMMPACT) recommendations for measures of significance and standardised measurement outcomes.

- Difficultty with knowing the effective dose or duration for many non-pharmacological interventions due to lack of definitive mechanisms.

Non-pharmacological interventions are therapist- and operatordependent and may be prone to multiple combined mechanisms or 'bundled effects' (Bennett 2011). Suggestions for future improvements in quality of evidence include robust studies emphasising on the mechanisms of pain in MS.

\section{Quality of the evidence}

All 10 included studies were rated as ' very low' quality for methodological evidence due to risk of bias and flaws in their methodological design (Figure 2; Figure 3).

- Lack of reporting of blinding and blinding processes (CastroSanchez 2012; Ehde 2015; Jensen 2009; Jensen 2016; Nazari 2016; Palm 2016).

- Underpowered from low sample size and lack of study power calculation. 
- Lack of reporting in IMMPACT suggestion of $>30 \%$ or $50 \%$ change in pain scores for clinical significance.

- Limited reporting of complete data.

- Lack of allocation concealment (Ayache 2016; Castro-Sanchez 2012; Hughes 2009; Jensen 2009; Jensen 2016; Mori 2010; Nazari 2016; Palm 2016; Warke 2006).

- Unclear in the reporting of study authors' conflicts of interest, funding sources (Palm 2016; Warke 2006).

- Diffilculty controlling for therapist-dependent bias, patient motivation and activity/interventions outside of treatment.

In summary, these limitations affected the quality of the evidence and highlights the importance of good methodological practices in research. This is specially important given the difficulty in recruitment of targeted study cohorts (with adequate sample sizes) and difficulties associated with controlling for patients' personal and other confounding factors such as, patient motivation and self-efficacy, comorbidity and activity level outside of therapy programmes), which influence compliance and delivery of therapy, thus impacting on outcomes.

\section{Potential biases in the review process}

The review authors followed a number of steps to ensure the reduction of bias in the review process. First, the review authors independently reviewed and assessed all articles. Second, the review authors adhered strictly to the inclusion and exclusion criteria for the studies and extraction and interpretation of the data, and followed the GRADE handbook. However, a number of limitations in the methodological quality of the review itself, and the completeness of the retrieved literature, cannot be ruled out. Despite the extended range of terms that were used to capture the widest possible selection of the relevant literature, we were not able to rule out some degree of selection bias from the literature search (van Tulder 2003). Possibility of publication bias cannot be omitted as we were not able to include negative trials or other trials which are yet to be published in academic literature (Egger 1998). Further, reference bias (Goetzsche 1987) is a further possibility, as we searched only reference lists within the relevant papers for additional articles. We welcome contact from any readers who are aware of important high-quality studies which are not included in this review.

\section{Agreements and disagreements with other studies or reviews}

There are limited systematic reviews in the area of nonpharmacological management of chronic pain in MS. This review highlights existing evidence and gaps in the literature. There are some similarities which are consistent between this review and another published non-Cochrane systematic review (Jawahar 2014). However, there are methodological differences of this review and the review by Jawar et al (Jawahar 2014). specifically inclusion of only high-quality studies (randomised controlled trials (RCTs) and clinical controlled trials (CCTs)) and use of standardised tools - theCochrane Handbook for Systematic Reviews of Interventions (Higgins 2011) and the 'GRADE' for the methodology and interpretation of findings. We think this review addressed the methodological issues in systematically reviewing the evidence for the management of chronic pain in pwMS (Bennett 2011). This is reflected in the findings of various issues within the included studies in this review, included blinding, small sample sizes, determination of the right dose/duration of treatment and focus on other outcome measures other than pain intensity such as adverse effects and patient compliance and adherence to therapy.

\section{AUTHORS' CONCLUSIONS}

\section{Implications for practice}

Despite use of a range of non-pharmacological interventions for the treatment of chronic pain in persons with multiple sclerosis (pwMS), this review found 'very low-level' evidence for the use of such interventions. Therefore, it is difficult to recommend routine use of non-pharmacological interventions alone for the treatment of chronic pain in an MS population. However, findings suggest that use of non-pharmacological intervention in combination with pharmacological agents is reasonable. The findings of this review also highlight the existing gaps in the literature and emphasise the need for robust evidence to support these modalities. Clinician involvement is vital to build evidence from everyday clinical practice. The clinical applicability of findings of this review need to be confirmed in future studies with robust study design, larger sample sizes and long-term follow-up.

\section{Implications for research}

This review shows that there are significant gaps in the literature on non-pharmacological management of chronic pain in MS. Future research implications include the following.

- Robust studies with reduced risk of bias, with adequate allocation, randomisation procedures

- Standard reporting of pain as defined by the Initiative on Methods, Measurement, and Pain Assessment in Clinical Trials (IMMPACT) (Dworkin 2008)

- Reporting pain measures desired by patients (Moore 2013)

- Appropriate and careful selection of study cohort and larger sample size

- Emphasise on details of pain mechanism, localisation pattern, severity and impact on everyday function

- Impact and burden on carer and family, or both

- Intervention-related adverse effects/complications

- Long-term impact of interventions

- Cost associated with the interventions

\section{ACK N O WLEDGEMENTS}

We are grateful to the Cochrane Multiple Sclerosis and Rare Diseases of the CNS Group Editorial Board for their support and assistance and $\mathrm{Dr}$ Kevin Young for his assistance in protocol preparation. We also like to thank Professor Andrew Moore and the editors for reviewing the manuscript. 


\section{R E F E R E N C E S}

\section{References to studies included in this review}

Ayache 2016 \{published data only\}

Ayache SS, Palm U, Chalah MA, Al-Ani T, Brignol A, Abdellaoui M, et al. Prefrontal tDCS decreases pain in patients with multiple sclerosis. Frontiers in Neuroscience 2016;10:147-51.

\section{Castro-Sanchez 2012 \{published data only\}}

Castro-Sanchez AM, Mataran-Penarrochal GA, Lara-Palomo I, Saavedra-Hernandez M, Arroyo-Morales M, Moreno-Lorenzo C. Hydrotherapy for the treatment of pain in people with multiple sclerosis: a randomized controlled trial. Evidence-Based Complementary and Alternative Medicine 2012;12:1-8.

Ehde 2015 \{published data only\}

Ehde DM, Elzea JL, Verrall AM, Gibbons LE, Smith AE, Amtmann D. Efficacy of a telephone-delivered self-management intervention for persons with multiple sclerosis: a randomized controlled trial with a one-year follow-up. Archives of Physical Medicine and Rehabilitation 2015;96(11):1945-58.

\section{Hughes 2009 \{published data only\}}

Hughes CM, Smyth S, Lowe-Strong AS. Reflexology for the treatment of pain in people with multiple sclerosis: a doubleblind randomised sham-controlled clinical trial. Multiple Sclerosis 2009;15(11):1329-38.

\section{Jensen 2009 \{published data only\}}

Jensen MP, Barber J, Romano JM, Molton IR, Raichle KA, Osborne TL, et al. A comparison of self-hypnosis versus progressive muscle relaxation in patients with multiple sclerosis and chronic pain. International Journal of Clinical and Experimental Hypnosis 2009;57(2):198-221.

\section{Jensen 2016 \{published data only\}}

Jensen MP, Gianas A, George HR, Sherlin LH, Kraft GH, Ehde DM. Use of neurofeedback to enhance response to hypnotic analgesia individuals with multiple sclerosis. International Journal of Clinical and Experimental Hypnosis 2016;64(1):1-23.

\section{Mori 2010 \{published data only\}}

Mori F, Codeca C, Kusayanagi H, Monteleone F, Buttari F, Fiore S, et al. Effects of anodal transcranial direct current stimulation on chronic neuropathic pain in patients with multiple sclerosis. Journal of Pain 2010;11(5):436-42.

\section{Nazari 2016 \{published data only\}}

Nazari F, Soheili M. A comparison of the effects of reflexology and relaxation on pain in women with multiple sclerosis. Journal of Complementary and Integrative Medicine 2016;13(1):65-71.

\section{Palm 2016 \{published data only\}}

Palm U, Chalah MA, Padberg F, Al-Ani T, Abdellaoui M, Sorel M, et al. Effects of transcranial random noise stimulation (tRNS) on affect, pain and attention in multiple sclerosis. Restorative Neurology and Neuroscience 2016;34(2):189-99.
Warke 2006 \{published data only\}

Warke K, Al-Smadi J, Baxter GD, Walsh DM, Lowe-Strong AS Efficacy of transcutaneous electrical nerve stimulation (TENS) for chronic low-back pain in a multiple sclerosis population: a randomized, placebo-controlled clinical trial. Clinical Journal of Pain 2006;22(9):812-9.

\section{References to studies excluded from this review}

\section{Anninos 2016 \{published data only\}}

Anninos P, Adamopoulos A, Kotini A, Tsagas N. MEG evaluation of pico-Tesla external TMS on multiple sclerosis patients. Multiple Sclerosis and Related Disorders 2016;8:45-53.

Backus 2016 \{published data only\}

Backus D, Manella C, Bender A, Ruger L, Long, M. Massage therapy may help manage fatigue, pain and spasticity in people with multiple sclerosis. Clinical Rehabilitation 2013;27(12):1126-36.

\section{Barlow 2009 \{published data only\}}

Barlow J, Turner A, Edwards R, Gilchrist M. A randomised controlled trial of lay-led self-management for people with multiple sclerosis. Patient Education and Counseling 2009;77(1):81-9.

\section{Catena 2014 \{published data only\}}

Catena L, Bacci L, Lombrano D, Morici C, Morgantini A. The effects of Pilates-fisios on pain, motor fatigue, and quality of life in patients with multiple sclerosis: a randomized controlled clinical trial. Multiple Sclerosis 2014;20(7):982.

\section{Doulatabad 2012 \{published data only\}}

Doulatabad SN, Nooreyan K, Doulatabad AN, Noubandegan ZM. The effects of pranayama, hatha and raja yoga on physical pain and the quality of life of women with multiple sclerosis. African Journal of Traditional, Complementary, and Alternative Medicines 2012;10(1):49-52.

\section{Hasanpour-Dehkordi 2015 \{published data only\}}

Hasanpour DA. Influence of yoga and aerobics exercise on fatigue, pain and psychosocial status in patients with multiple sclerosis: a randomized trial. Journal of Sports Medicine and Physical Fitness 2015;56(11):1417-22.

\section{Hasanpour-Dehkordi 2016 \{published data only\}}

Hasanpour-Dehkordi A, Jivad N, Solati K. Effects of yoga on physiological indices, anxiety and social functioning in multiple sclerosis patients: a randomized trial. Journal of Clinical and Diagnostic Research 2016;10(6):VC01-05.

\section{Jensen 2007 \{published data only\}}

Jensen MP, Barber J, Hanley MA, Raichle KA, Osborne TL, Molton IR, et al. The effects of self-hypnosis training on pain in persons with multiple sclerosis. Focus on Alternative \& Complementary Therapies 2007;12(s1):28-9. 
Jensen 2011 \{published data only\}

Jensen MP, Ehde DM, Gertz KJ, Stoelb BL, Dillworth TM, Hirsh AT, et al. Effects of self-hypnosis training and cognitive restructuring on daily pain intensity and catastrophizing in individuals with multiple sclerosis and chronic pain. International Journal of Clinical and Experimental Hypnosis 2011;59(1):45-63.

\section{Marinelli 2015 \{published data only\}}

Marinelli L, Mori L, Solaro C, Uccelli A, Pelosin E, Curra A, et al. Effect of radial shock wave therapy on pain and muscle hypertonia: a double-blind study in patients with multiple sclerosis. Multiple Sclerosis Journal 2015;21(5):622-9.

Mathiowetz 2005 \{published data only\}

Mathiowetz VG, Finlayson ML, Matuska KM, Chen HY, Luo P. Randomized controlled trial of an energy conservation course for persons with multiple sclerosis. Multiple Sclerosis 2005;11(5):592-601.

\section{McGuire 2015 \{published data only\}}

McGuire KB, Stojanovic-Radic J, Strober L, Chiaravalloti ND, DeLuca J. Development and effectiveness of a psychoeducational wellness program for people with multiple sclerosis: description and outcomes. International Journal of MS Care 2015;17(1):1-8.

\section{Negahban 2013 \{published data only\}}

Negahban H, Rezaie S, Goharpey S. Massage therapy and exercise therapy in patients with multiple sclerosis: a randomized controlled pilot study. Clinical Rehabilitation 2013;27(12):1126-36.

\section{Oken 2004 \{published data only\}}

Oken BS, Kishiyama S, Zajdel D, Bourdette D, Carlsen J, Haas M, et al. Randomized controlled trial of yoga and exercise in multiple sclerosis. Neurology 2004;62(11):2058-64.

\section{Pilutti 2013 \{published data only\}}

Pilutti L, Dlugonski D, Sandroff B, Klaren R, Motl R. Randomized controlled trial of a behavioral intervention targeting symptoms and physical activity in multiple sclerosis. Multiple Sclerosis 2014;20(5):594-601.

\section{Pozzilli 2002 \{published data only\}}

Pozzilli C, Brunetti M, Amicosante AM, Gasperini C, Ristori G, Palmisano L, et al. Home based management in multiple sclerosis: results of a randomised controlled trial. Journal of Neurology, Neurosurgery, and Psychiatry 2002;73(3):250-5.

\section{Seada 2013 \{published data only\}}

Seada YI, Nofel R, Sayed HM. Comparison between trans-cranial electromagnetic stimulation and low-level laser on modulation of trigeminalneuralgia. Journal of Physical Therapy Science 2013;25(8):911-4.

\section{Smedal 2011 \{published data only\}}

Smedal T, Myhr K-M, Aarseth JH, Gjelsvik B, Beiske AG, Glad SB, Strand LI. The influence of warm versus cold climate on the effect of physiotherapy in multiple sclerosis. Acta Neurologica Scandinavica 2011;124(1):45-52.

\section{Storr 2006 \{published data only\}}

Storr LK, Sorensen PS, Sorensen M. The efficacy of multidisciplinary rehabilitation in stable multiple sclerosis patients. Multiple Sclerosis 2006;12(2):235-42.

Van der Linden 2013 \{published data only\}

Van der Linden ML, Bulley C, Geneen LJ, Hooper JE, Cowan P, Mercer TH. Pilates for people with multiple sclerosis who use a wheelchair: feasibility, efficacy and participant experiences. Disability and Rehabilitation 2013;36(11):1-8.

\section{Additional references}

\section{Al Smadi 2003}

Al-Smadi J, Warke K, Wilson I, Cramp AF, Noble G, Walsh DM, et al. A pilot investigation of the hypoalgesic effects of transcutaneous electrical stimulation upon lower back in people with multiple sclerosis. Clinical Rehabilitation 2003;17(7):742-9.

\section{Al-Araji 2005}

Al-Araji AH, Oger J. Reappraisal of Lhemitte's sign in multiple sclerosis. Multiple Sclerosis 2005;11:398-402.

\section{Albert 1969}

Albert ML. Treatment of pain in multiple sclerosis - preliminary report. New England Journal of Medicine 1969;280(25):1395.

\section{Amatya 2013}

Amatya B, Khan F, La Mantia L, Demetrios M, Wade DT. Non pharmacological interventions for spasticity in multiple sclerosis. Cochrane Database of Systematic Reviews 2013, Issue 2. [DOI: 10.1002/14651858.CD009974.pub2]

\section{Ansari 2009}

Ansari NN, Naghdi S, Hasson S, Fakhari Z, Mashayekhi M, Herasi M. Assessing the reliability of the Modified Ashworth Scale between two physiotherapists in adult patients with hemiplegia. NeuroRehabilitation 2009;25(4):235-40.

\section{Archibald 1994}

Archibald CJ, McGrath PJ, Ritvo PG, Fisk JD, Bahn V, Maxner CE, et al. Pain prevalence, severity and impact in a clinic sample of multiple sclerosis. Pain 1994;58:89-93.

\section{Beck 1961}

Beck AT, Ward CH, Mendelson M, Mock J, Erbaugh J. An inventory for measuring depression. Archives of General Psychiatry 1961;4:561-71.

\section{Bennett 2011}

Bennett MI, Closs SJ. Methodological issues in non pharmacological trials for chronic pain. Anaesthesia, Pain and Intensive Care 2011;15:126-32.

\section{Beric 1998}

Beric A. Central pain and dysesthesia syndrome. Neurolgy Clinics 1998;16(4):899-918. 


\section{Blyth 2001}

Blyth FM, March LM, Barnabie AJ, Jorm LR, Williamson M, Cousins MJ. Chronic pain in Australia: a prevalence study. Pain 2001;89:127-34.

\section{Blyth 2003}

Blyth FM, March LM, Cousins MJ. Chronic pain related disability and use of analgesia and health services in a Sydney community. Medical Journal of Australia 2003;179:84-7.

\section{Boivie 1999}

Boivie J. Central pain. In: Wall PD, Melzack R editor(s). Textbook of Pain. New York: Churchill Livingstone, 1999:879-914.

\section{Boldt 2011}

Boldt I, Eriks-Hoogland I, Brinkhof MW, Bie RA, Von Elm E. Nonpharmacological interventions for chronic pain in people with spinal cord injury. Cochrane Database of Systematic Reviews 2014, Issue 11. [DOI: 10.1002/14651858.CD009177.pub2]

\section{Cleeland 1989}

Cleeland C. Measurement of pain by subjective report. Advances in Pain Research and Therapy: Issues in Pain Measurement. Vol. 12, New York: Raven Press, 1989:391-403.

\section{Clifford 1984}

Clifford DB, Trotter JL. Pain in multiple sclerosis. Archives of Neurology 1984;41(12):1270-2.

\section{Compston 1998}

Compston A. Distribution of multiple sclerosis. In: Compston A, Ebers G, Lassmann H, McDonald I, Matthews B, Wekerle H editor(s). McAlpine's Multiple Sclerosis. 3rd Edition. London: Churchill Livingstone, 1998:63-100.

\section{Cutter 2000}

Cutter NC, Scott DD, Johnson JC, Whiteneck G. Gabapentin effect on spasticity in multiple sclerosis: a placebocontrolled, randomised trial. Archives of Physical Medicine and Rehabilitation 2000;81:164-9.

\section{Detels 1978}

Detels R, Visscher B, Haile R, Malmgren R, Dudley J, Coulson A. Multiple sclerosis and age at migration. American Journal of Epidemiology 1978;108:386-93.

\section{Dworkin 2008}

Dworkin RH, Turk DC, Wyrwich KW, Beaton D, Cleeland CS, Farrar JT, et al. Interpreting the clinical importance of treatment outcomes in chronic pain clinical trials: IMMPACT recommendations. Pain 2008;9(2):105-21.

\section{Egger 1998}

Egger M, Smith GD. Bias in location and selection of studies. BMJ 1998;16(7):61-6.

\section{Ehde 2003}

Ehde DM, Gibbons LE, Chwastiak L, Bombardier CH, Sullivan MD, Kraft GH. Chronic pain in a large community sample of persons with multiple sclerosis. Multiple Sclerosis 2003;9:606-11.

\section{Ehde 2005}

Ehde DM, Osborne TL, Jensen MP. Chronic pain in persons with multiple sclerosis. Physical Medicine and Rehabilitation Clinics North America 2005;14:503-12.

\section{Ensari 2016}

Ensari I, Motl R, McAuley E. Structural and construct validity of the Leeds Multiple Sclerosis Quality of Life scale. Quality of Life Research 2016;25(6):1605-11.

\section{Finlayson 2011}

Finlayson M, Preissner K, Cho C, Plow M. Randomized trial of a teleconference-delivered fatigue management program for people with multiple sclerosis. Multiple Sclerosis 2011;17(9):1130-40.

\section{Fisk 1994}

Fisk JD, Ritvo PG, Ross L, Haase DA, Marrie TJ, Schlech WF. Measuring the functional impact of fatigue: initial validation of the fatigue impact scale. Clinical Infectious Diseases 1994;18:S79-83.

\section{Foley 2013}

Foley PL, Vesterinen HM, Laird BJ, Sena ES, Colvin LA, Chandran S, et al. Prevalence and natural history of pain in adults with multiple sclerosis: systematic review and metaanalysis. Pain 2013;154(5):632-42.

\section{Fordyce 1973}

Fordyce WE, Fowler RS, Lehman JF, Delateur BJ, Sand PL, Trieschmann RB. Operant conditioning in the treatment of chronic pain. Archives of Physical Medicine and Rehabilitation 1973;54:399-408.

\section{Gilworth 2003}

Gilworth G, Chamberlain MA, Harvey A. Development of a work instability scale for rheumatoid arthritis. Arthritis and Rheumatism 2003;49:349-54.

\section{Goetzsche 1987}

Goetzsche PC. Reference bias in reports of drug trials. British Medical Journal 1987;295:654-6.

\section{Granger 1998}

Granger CV. The emerging science of functional assessment: our tool for outcomes analysis. Archives of Physical Medicine and Rehabilitation 1998;79:235-40.

\section{Hammond 1988}

Hammond SR, McLeod JG, Millingens KS, Stewart-Wynne EG, English D, Holland JT, et al. The epidemiology of multiple sclerosis in three Australian cities: Perth, Newcastle and Hobart. Brain 1988;111:1-25.

\section{Hans 2003}

Hans BC, Willis WD, Hulsebosch CE. Temporal plasticity of dorsal horn somatosensory neurons after acute and chronic spinal cord hemisection in rat. Brain Research 2003;970:238-41. 


\section{Harding 1998}

Harding VR, Simmonds MJ, Watson PJ. IASP Clinical Update. Vol. 6, IASP, 1998.

\section{Heckman-Stone 2001}

Heckman-Stone C, Stone C. Pain management techniques used by patients with multiple sclerosis. Journal of Pain 2001;2:205-8.

\section{Higgins 2011}

Higgins JPT, Green S, editor(s). Cochrane Handbook for Systematic Reviews of Interventions. Chichester (UK): John Wiley \& Sons, 2008.

\section{Hobart 2001}

Hobart J. The Multiple Sclerosis Impact Scale (MSIS-29): a new patient-based outcome measure. Brain 2001;124(5):962-73.

\section{Hobart 2006}

Hobart JC, Riazi A, Thompson AJ, Styles IM, Ingram W, Vickery PJ, et al. Getting the measure of spasticity in multiple sclerosis: The Multiple Sclerosis Spasticity Scale (MSSS-88). Brain 2006;129:224-34.

\section{Hurst 2004}

Hurst $\mathrm{H}$, Bolton J. Assessing the clinical significance of change scores recorded on subjective outcome measures. Journal of Manipulative and Physiological Therapeutics 2004;27:26-35.

\section{Jawahar 2014}

Jawahar R, Oh U, Yang S, Lapane KL. Alternative approach: a systematic review of non-pharmacological non-spastic and non-trigeminal pain management in multiple sclerosis. European Journal of Physical and Rehabilitation Medicine 2014;50(5):567-77.

\section{Jensen 1994}

Jensen MP, Turner JA, Romano JM, Lawler BK, Brian K. Relationship of pain specific beliefs to chronic pain adjustment. Pain 1994;57:301-9.

\section{Jensen 1999}

Jensen MP, Romano JM, Turner JA, Lawler BK. Patient beliefs predict patient functioning: further support for a cognitivebehavioral model of chronic pain. Pain 1999;81:95-104.

\section{Jensen 2001}

Jensen MP, Karoly P. Self-report scales and procedures for assessing pain in adults. In: Turk DC, Melzack R editor(s). Handbook of Pain Assessment. USA: Guilford Press, 2001:15-34.

\section{Karjalainen 2003}

Karjalainen KA, Malmivaara A, Van Tulder MW, Roine R, Jauhiainen M, Hurri $\mathrm{H}$, et al. Multidisciplinary biopsychosocial rehabilitation for sub-acute low-back pain among working age adults. Cochrane Database of Systematic Reviews 2003, Issue 4. [DOI: 10.1002/14651858.CD002193]

\section{Khan 2007a}

Khan F, Pallant J. Chronic pain in multiple sclerosis: prevalence, characteristics, and impact on quality of life in an Australian community cohort. Journal of Pain 2007;8:614-23.

\section{Khan 2007b}

Khan F, Turner-Stokes L, Ng L, Kilpatrick T, Amatya B. Multidisciplinary rehabilitation for adults with multiple sclerosis. Cochrane Database of Systematic Reviews 2007, Issue 2. [DOI: 10.1002/14651858.CD006036.pub2]

\section{Khan 2011}

Khan F, Pallant JF, Amatya B, Young K, Gibson S. Cognitivebehavioral classifications of chronic pain in persons with multiple sclerosis. International Journal of Rehabilitation Research. Internationale Zeitschrift fur Rehabilitationsforschung. Revue Internationale de Recherches de Readaptation 2011;34:235-42.

\section{Khan 2013}

Khan F, Amatya B, Kesselring J. Longitudinal 7-year followup of chronic pain in persons with multiple sclerosis in the community. Journal of Neurology 2013;206(8):2005-31.

\section{Kraft 2005}

Kraft GH, Cui JY. Multiple sclerosis. In: Delisa JA editor(s). Physical Medicine \& Rehabilitation: Principles \& Practice. Philadelphia: Lipincott Williams \& Wilkins, 2005:1753-69.

\section{Kroenke 2001}

Kroenke K, Spitzer RL, Williams JB. Patient Health Questionnaire (PHQ-9). Journal of General Internal Medicine 2001;16(9):606-13

\section{Krupp 1989}

Krupp LB, LaRocca NG, Muir-Nash J, Steinberg AD. The Fatigue Severity Scale: application to patients with multiple sclerosis and systemic lupus erythematosus. Archives of Neurology 1989;46(10):1121-3.

\section{Kurtzke 1983}

Kurtzke JF. Rating neurological impairment in multiple sclerosis: an expanded disability status scale (EDSS). Neurology 1983;33:1444-52.

\section{Lalkhen 2012}

Lalkhen AG, Bedford JP, Dwyer AD. Pain associated with multiple sclerosis: epidemiology, classification and management. British Journal of Neuroscience Nursing 2012;8(5):267-74

\section{Larson 2013}

Larson R. Psychometric properties of the modified fatigue impact scale. International Journal of MS Care 2013;15(1):15-20.

\section{Lovibond 1995}

Lovibond SH, Lovibond PF. Manual for the depression anxiety stress scales. trove.nla.gov.au/work/30421447 (accessed 10/10/2016).

\section{Ma 2014}

Ma VY, Chan L, Carruthers KJ. Incidence, prevalence, costs, and impact on disability of common conditions requiring rehabilitation in the United States: stroke, spinal cord injury, traumatic brain injury, multiple sclerosis, osteoarthritis, 
rheumatoid arthritis, limb loss, and back pain. Archives of Physical Medicine and Rehabilitation 2014;95(5):986-95.

\section{Mahoney 1965}

Mahoney FI, Barthel D. Functional evaluation: the Barthel Index. Maryland State Medical Journal 1965;14:56-61.

\section{McDonald 2001}

McDonald WI, Compston A, Edan G, Goodkin D, Hartung HP, Lublin FD, et al. Recommended diagnostic criteria for MS: guidelines from the international panel on the diagnosis of MS. Annals of Neurology 2001;59(1):121-7.

\section{Melzack 1975}

Melzack R. The McGill Pain Questionnaire: major properties and scoring methods. Pain 1975;1:277-99.

\section{Melzack 1987}

Melzack R. The short-form McGill Pain Questionnaire. Pain 1987;30:191-7.

\section{Merskey 1994}

Merskey H, Bogduk N. Classification of Chronic Pain: Descriptions of Chronic Pain Syndromes and Definitions of Pain Terms. 2nd Edition. Seattle: IASP Press, 1994.

\section{Moore 2013}

Moore R, Straube S, Aldington D. Pain measures and cut-offs - 'no worse than mild pain' as a simple, universal outcome. Anaesthesia 2013;68(4):400-12.

\section{Moulin 1988}

Moulin DE, Foley KM, Ebers GC. Pain syndromes in multiple sclerosis. Neurology 1988;38(12):1830-4.

\section{MS Society 2011}

MS Society Australia. MS Australia. www.msaustralia.org.au/ (accessed 10 October 2016).

\section{O'Gormann 2012}

O'Gorman C, Lucas R, Taylor B. Environmental risk factors for multiple sclerosis: a review with a focus on molecular mechanisms. International Journal of Molecular Sciences 2012;13(9):11718-52.

\section{Review Manager 2014 [Computer program]}

Nordic Cochrane Centre, The Cochrane Collaboration. Review Manager 5 (RevMan 5). Version 5.3. Copenhagen: Nordic Cochrane Centre, The Cochrane Collaboration, 2014.

\section{Robinson 1983}

Robinson BC. Validation of a Caregiver Strain Index (CSI). Journal of Gerontology 1983;38(3):344-8.

\section{$\operatorname{Rog} 2005$}

Rog DJ, Nurmikko TJ, Friede T, Young CA. Randomized, controlled trial of cannabis-based medicine in central pain in multiple sclerosis. Neurology 2005;65(6):812-9.

\section{Rossi 2009}

Rossi S, Mataluni G, Codeca C, Fiore S, Buttari F, Musella A, et al. Effects of levetiracem on chronic pain in multiple sclerosis: results of a pilot, randomized, placebo-controlled study. European Journal of Neurology 2009;16:360-6.

\section{Saifuddin 2014}

Saifuddin E, Ng L, Amatya B, Khan F. Chronic pain in multiple sclerosis: an overview. American Journal of Internal Medicine 2014;2(2):20-5.

\section{Shahrbanian 2013}

Shahrbanian S, Auais M, Duguette P, Anderson K, Mayo N. Does pain in individuals with multiple sclerosis affect employment? A systematic review and meta-analysis. Pain Research and Management 2013;18(5):e94-e100.

\section{Shakespeare 2003}

Shakespeare D, Bogglid M, Young CA. Anti-spasticity agents for multiple sclerosis. Cochrane Database of Systematic Reviews 2003, Issue 4. [DOI: 10.1002/14651858.CD001332]

\section{Shibasaki 1974}

Shibasaki $\mathrm{H}$, Kuroiwa Y. Painful tonic seizure in multiple sclerosis. Archives of Neurology 1974;30:47-51.

\section{Simmonds 1996}

Simmonds MJ, Kumar S, Lechelt E. Psychosocial factors in disabling low back pain: causes or consequences. Disability and Rehabilitation 1996;18(4):161-8.

\section{Snaith 2003}

Snaith R. Hospital Anxiety and Depression scale (HADS). Health and quality of life outcomes 2003;1(1):29.

\section{Stenager 1991}

Stenager E, Knudsen L, Jensen K. Acute and chronic pain syndrome in multiple sclerosis. Acta Neurologica Scandinavica 1991;84(3):197-200.

\section{Stevens 2016}

Stevens M, Lin L, Maher C. The Roland Morris Disability Questionnaire. Journal of Physiotherapy 2016;62(2):116.

\section{Sullivan 1992}

Sullivan MJL, Edgeley K, Mikail S, Dehoux E. Psychological correlates of health care utilization in chronic illness. Canadian Journal of Rehabilitation 1992;6:13-21.

\section{Svendson 2003}

Svendson KB, Jensen TS, Overvad K, Hansen HJ, KochHenderson N, Bach FW. Pain in patients with multiple sclerosis: a population based study. Archives of Neurology 2003;60(8):1089-94.

\section{Thomas 2006}

Thomas PW, Thomas S, Hillier C, Galvin K, Baker R. Psychological interventions for multiple sclerosis. Cochrane Database of Systematic Reviews 2006, Issue 1. [DOI: 10.1002/14651858.CD004431.pub2] 


\section{Treede 2008}

Treede RD, Jensen TS, Campbell JN, Cruccu G, Dostrovsky JO, Griffin JW, et al. Neuropathic pain: redefinition and a grading system for clinical and research purposes. Neurology 2008;70:1630-5.

\section{Trisolini 2010}

Trisolini M, Honeycutt A, Wiener J, Lesesne S. Global economic impact of multiple sclerosis: a literature review. www.msif.org/ wp-content/uploads/2014/09/ExecSummary_English.pdf Vol. (accessed 10 October 2016).

\section{Truini 2013}

Truini A, Barbanti P, Pozzilli C, Cruccu G. A mechanism-based classification of pain in multiple sclerosis. Journal of Neurology 2013;260(2):351-67.

\section{van Tulder 2003}

van Tulder MW, Furlan A, Bombardier C, Bouter L. Updated method guidelines for systematic reviews in the Cochrane Collaboration Back Review Group. Spine 2003;28(12):1290-9.

\section{Vermote 1986}

Vermote $\mathrm{R}$, Ketelaer $\mathrm{P}$, Carton $\mathrm{H}$. A prospective study using the McGill pain questionnaire. Clinical Neurology and Neurosurgery 1986;88(2):87-93.

\section{Vickrey 1995}

Vickrey BG, Hays RD, Harooni R, Myers LW, Ellison GW. Health related quality of life measure for multiple sclerosis. Quality of Life Research 1995;4:187-206.

\section{Von Korff 1992}

Von Korff M, Ormel J, Keefe FJ, Dworkin SF. Grading the severity of chronic pain. Pain 1992;50:130-49.

\section{CHARACTERISTICS OF STUDIES}

Characteristics of included studies [ordered by study ID]

\section{Ware 2000}

Ware JE Jr. SF-36 health survey update. Spine 2000;25(24):3130-9.

\section{Warke 2004}

Warke K, Al-Smadi J, Baxter GD, Walsh DM, Lowe-Strong AS. Use of self-applied TENS for low back pain in people with multiple sclerosis. International Journal of Therapy and Rehabilitation 2004 Jun;11(6):275-80.

\section{Warnell 1991}

Warnell P. The pain experience of a multiple sclerosis population: a descriptive study. Axone 1991;13:26-8.

\section{WHO 2008}

World Health Organization (WHO). Atlas: Multiple sclerosis resources in the world. www.who.int/mental_health/neurology/ Atlas_MS_WEB.pdf (accessed 10 October 2016).

\section{Zaider 2003}

Zaider TI, Heimberg RG, Fresco DM, Schneier FR, Liebowitz MR. Evaluation of the clinical global impression scale among individuals with social anxiety disorder. Psychological Medicine 2003;33(4):611-22.

\section{References to other published versions of this review Amatya 2017}

Amatya B, Young J, Khan F. Non-pharmacological interventions for chronic pain in multiple sclerosis. Cochrane Database of Systematic Reviews 2017, Issue 3. [DOI: 10.1002/14651858.CD012622]

Ayache 2016

$\begin{array}{ll}\text { Methods } & \text { - Randomised sham-controlled trial,cross-over and double-blinded study } \\ \text { - Randomisation through computer generation } \\ \text { - Study conducted in France }\end{array}$

Participants

Population source: participants enrolled from Neurology Department of Henri Mondor Hospital.

Numbers: randomised 16, anodal transcranial direct current stimulation 8 , sham 8

Inclusion criteria:age 18-70 years, definitively diagnosed with multiple according to McDonalds Criteria, right-handedness based on Edinburgh Inventory, neuropathic pain $>3$ months as per Neuropathic Pain Symptom Inventory, VAS > 40 over average 1 week

Exclusion criteria: multiple sclerosis relapses within last 2 months, changes in pharmacological and physiotherapy in last month, presence of comorbid neurodegenerative or psychiatric disorders, history of substance abuse, absence of measurable pain-related evoked potentials at right hand, severe deficits in visual acuity and fields by examination, severe upper limb impairment by Medical Research Council for muscle power. 
Ayache 2016 (Continued)

Age: mean age 48.9 years, range $38-67$ years

Gender: women 13 , men 3

Type of MS: relapsing remitting 11, secondary progressive 4, primary progressive 1

Pain type: neuropathic pain

Interventions

Treatment: anodal tDCS, $2 \mathrm{~mA}$ current

Control: sham tDCS

Duration: 3

consecutive days of tDCS stimulation (20-minute sessions), at least 3 weeks washout period

\begin{tabular}{ll}
\hline Outcomes & $\cdot$ VAS \\
& - BPI \\
& MFIS \\
& HADS \\
& CRQ \\
& CGI
\end{tabular}

Notes

Funding: authors had received grants and gave lectures.

Conflicts of interest: authors declared no commercial of financial relationships that could act as conflict of interest

\section{Risk of bias}

\begin{tabular}{|c|c|c|}
\hline Bias & Authors' judgement & Support for judgement \\
\hline $\begin{array}{l}\text { Random sequence genera- } \\
\text { tion (selection bias) }\end{array}$ & Low risk & $\begin{array}{l}\text { The randomisation schedule was generated prior to the beginning of the study } \\
\text { using a dedicated software }\end{array}$ \\
\hline $\begin{array}{l}\text { Allocation concealment } \\
\text { (selection bias) }\end{array}$ & Unclear risk & No information provided \\
\hline $\begin{array}{l}\text { Blinding of participants } \\
\text { and personnel (perfor- } \\
\text { mance bias) } \\
\text { All outcomes }\end{array}$ & Low risk & Participants were blind to treatment \\
\hline $\begin{array}{l}\text { Blinding of outcome as- } \\
\text { sessment (detection bias) } \\
\text { All outcomes }\end{array}$ & Low risk & Participants were blind to treatment \\
\hline $\begin{array}{l}\text { Incomplete outcome data } \\
\text { (attrition bias) } \\
\text { All outcomes }\end{array}$ & Low risk & Attrition rated reported. None lost to follow-up \\
\hline $\begin{array}{l}\text { Selective reporting (re- } \\
\text { porting bias) }\end{array}$ & Low risk & All outcomes reported \\
\hline Other bias & Low risk & No other bias detected \\
\hline
\end{tabular}


Castro-Sanchez 2012

\begin{tabular}{ll}
\hline Methods & Randomised controlled trial \\
- Study conducted in Spain \\
- Randomisation through computer generation \\
\hline
\end{tabular}

Participants

Population source: participants were recruited from MS Association of Almeria in Spain.

Numbers: randomised 73, Ai Chi 36, control 37

Inclusion criteria: MS diagnosis, age between 18 and 75 years, VAS pain score $>4$ for at least two months, EDSS $\leq 7.5$

Exclusion criteria: treatment with another complementary and alternative medicine (either current or within the previous 3 month, relapse requiring hospitalisation or steroid treatment within the past 2 months

Age: experimental group (mean age 46 years, range 25-75), control group (mean age 50 years, range 29-75)

Gender: experimental group(26 women,10 men), control group (24 women,13 men)

Type of MS: experimental group (6 primary progressive, 9 secondary progressive, 21 unknown), control group (9 primary progressive, 12 secondary progressive, 16 unknown)

Pain type: musculoskeletal pain (back, cervical, legs, feet, arms, shoulder)

\begin{tabular}{ll} 
Interventions & Treatment: Ai Chi exercises \\
Control: relaxation & Duration: 20 weeks (twice a week), 4 sessions \\
\hline Outcomes & Primary \\
- VAS \\
- MPQ \\
- RMDQ \\
Secondary \\
- Spasm VAS \\
- MSIS29 \\
- MFIS
\end{tabular}

Notes

Funding: not described

Conflicts of interest: not described

\section{Risk of bias}

\begin{tabular}{lll}
\hline Bias & Authors' judgement & Support for judgement \\
\hline $\begin{array}{l}\text { Random sequence genera- } \\
\text { tion (selection bias) }\end{array}$ & Low risk & Computer-generated randomised list \\
\hline $\begin{array}{l}\text { Allocation concealment } \\
\text { (selection bias) }\end{array}$ & Unclear risk & Allocation concealment not described \\
\hline
\end{tabular}




\section{Castro-Sanchez 2012 (Continued)}

Blinding of participants High risk and personnel (performance bias)

All outcomes
Study could not guarantee that participants were blinded to the nature of their group because they were all members of the same association

Blinding of outcome as-
sessment (detection bias) $\quad$ Low risk $\quad$ Researcher blinded to group allocation

All outcomes

Incomplete outcome data Low risk

(attrition bias)

None lost to follow-up

All outcomes

\begin{tabular}{lll}
\hline $\begin{array}{l}\text { Selective reporting (re- } \\
\text { porting bias) }\end{array}$ & Low risk & All outcomes reported \\
\hline Other bias & Low risk & No other bias detected \\
\hline
\end{tabular}

Ehde 2015

$\begin{array}{ll}\text { Methods } & \text { Randomised controlled trial, single-blinded, parallel group and single centre } \\ \text { - Study conducted in the USA } \\ \text { - Randomisation through computer generation } \\ \text { - Allocation by limited access database program }\end{array}$

Participants

Population source: recruited from University of Washington Department of Rehabilitation Medicine Research. Registry and advertisements through National MS organisations. Flyers and referrals from University of Washington Multiple Sclerosis Centre.

Numbers: randomised 163, telephone self-management 75, control (telephone education) 88

Inclusion criteria: >18 years, self-reported physician diagnosis of MS and 1 or more of the following: (1) moderate depressive symptoms indicated by a score of 10 to 14 on the PHQ-9, presence of chronic pain (average pain intensity 3 in the past week) or significant fatigue symptoms, defined as a score 10 on the 5-item (MFIS)

Exclusion criteria: cognitive impairment (1 error on 6-item Cognitive Screener), psychotherapy more than once a month, had participated in another study for fatigue, depression, or pain, moderate-severe to severe depressive symptoms (PHQ-9 score 15)

Age: treatment group (mean age 51 years, range 25-76), control group (mean age 53.2 years, range 26-76)

Gender: treatment group (women 67, men 8), control group (women 75, men 13)

Type of MS: treatment group (relapsing remitting 46, progressive 29), control group (relapsing remitting 45, progressive 43)

Pain type: chronic pain

Interventions

Treatment: telephone self-management skills training

Control: education on MS symptoms

Duration: 8 weekly individual telephone calls delivered, 45-60 minute sessions

Outcomes Primary


Ehde 2015 (Continued)
- MFIS
- BPI
- PHQ-9
Secondary
- Pain NRS
- SES
- PANAS
- PAM
- SF8 Health Survey
- Patient Reported Outcomes Measurement Information System
- Conner Davidson Resilience Scale

Notes Funding: not described

Conflicts of interest: not described

\section{Risk of bias}

\begin{tabular}{|c|c|c|}
\hline Bias & Authors' judgement & Support for judgement \\
\hline $\begin{array}{l}\text { Random sequence genera- } \\
\text { tion (selection bias) }\end{array}$ & Low risk & Random numbers were generated by computer software \\
\hline $\begin{array}{l}\text { Allocation concealment } \\
\text { (selection bias) }\end{array}$ & Low risk & $\begin{array}{l}\text { The allocation sequence was concealed from the research assistants who en- } \\
\text { rolled participants via a limited access database program }\end{array}$ \\
\hline $\begin{array}{l}\text { Blinding of participants } \\
\text { and personnel (perfor- } \\
\text { mance bias) } \\
\text { All outcomes }\end{array}$ & Low risk & On 2 occasions research assistants became aware of a participant's allocation \\
\hline $\begin{array}{l}\text { Blinding of outcome as- } \\
\text { sessment (detection bias) } \\
\text { All outcomes }\end{array}$ & High risk & On 2 occasions research assistants became aware of a participant's allocation \\
\hline $\begin{array}{l}\text { Incomplete outcome data } \\
\text { (attrition bias) } \\
\text { All outcomes }\end{array}$ & High risk & $\begin{array}{l}\text { For the telephone self-management group there were } 10 \text { withdrawals during } \\
\text { sessions and } 4 \text { during assessments. For the control group there were } 6 \text { with- } \\
\text { drawals during sessions and } 2 \text { withdrawals during assessments }\end{array}$ \\
\hline $\begin{array}{l}\text { Selective reporting (re- } \\
\text { porting bias) }\end{array}$ & Low risk & All outcomes reported \\
\hline Other bias & Low risk & No other bias detected \\
\hline
\end{tabular}

Hughes 2009

Methods $\quad$ Randomised controlled trial,double-blinded
- Study in Northern Ireland
- Randomisation through computer-generated lists
Allocation concealment not described

Participants

Population source: responses to advertisement in local advertisement and MS charities.

Numbers: randomised 71,intervention 35, sham 36 
Inclusion criteria: 18-75 years of age, definite diagnosis of MS, pain greater than 4 on VAS of at least 2 months, EDSS of 7.5

Exclusion criteria: previous experience of reflexology, participation in research studies currently or within the previous 3 months relapse (requiring hospitalisation or steroid treatment) within the past 2 months

Age: reflexology group (mean age 50 years, range 26-75), sham group (mean age 53, range 34-74)

Gender: reflexology group (30 women,5 men),sham group (29 women,7 men)

Type of MS: precision reflexology group (benign 0, relapsing remitting 16, primary progressive 4, secondary progressive 6 , unknown 9), sham group (benign 1, relapsing remitting 12 , primary progressive 4 , secondary progressive 13 , unknown 6)

Pain type: musculoskeletal (low back pain, legs,feet,shoulders, hips arms,eye)

Control: standardised foot massage

Duration: 45-minute sessions weekly for 10 weeks

\begin{tabular}{ll}
\hline Outcomes & Primary \\
- VAS (Pain) \\
Secondary \\
- VAS (weekly pain scores) \\
- MPQ \\
- PRI \\
- PPI \\
- RMDQ \\
- MAS (Spasticity) \\
- MFIS \\
- FSS \\
- BDI2 \\
BI
\end{tabular}

Notes

Funding: National MS Society, USA and Action MS for their assistance with recruitment and the use of facilities

Conflicts of interest: none to declare

\section{Risk of bias}

\begin{tabular}{lll}
\hline Bias & Authors' judgement & Support for judgement \\
\hline $\begin{array}{l}\text { Random sequence genera- } \\
\text { tion (selection bias) }\end{array}$ & Low risk & Randomised by computer-generated list \\
\hline $\begin{array}{l}\text { Allocation concealment } \\
\text { (selection bias) }\end{array}$ & Unclear risk & Allocation concealment not described \\
\hline $\begin{array}{l}\text { Blinding of participants } \\
\text { and personnel (perfor- } \\
\text { mance bias) } \\
\text { All outcomes }\end{array}$ & Low risk & Participants were blinded to group allocation. \\
\hline
\end{tabular}


Hughes 2009 (Continued)
Blinding of outcome as-
Low risk
Investigator who was blinded to group allocation sessment (detection bias)

All outcomes

\begin{tabular}{lll}
$\begin{array}{l}\text { Incomplete outcome data } \\
\text { (attrition bias) } \\
\text { All outcomes }\end{array}$ & High risk & Five participants were lost to follow-up \\
\hline $\begin{array}{l}\text { Selective reporting (re- } \\
\text { porting bias) }\end{array}$ & Low risk & All outcomes in the review reported
\end{tabular}

Other bias Low risk No other bias detected

Jensen 2009

$\begin{array}{ll}\text { Methods } & \text { Randomised controlled clinical trial } \\ \text { - Study conducted in the USA } \\ \text { - Randomisation through computer-generated lists } \\ \text { - Allocation concealment not described }\end{array}$

Participants

Population source: recruited from previously completed survey of study of pain

Numbers: randomised 22, self-hypnosis first 8, self-hypnosis 7, progressive muscle relaxation 7

Inclusion criteria: diagnosis of MS, at least 18 years old, reported chronic daily pain that was rated as being at least $4 / 10$, on average, on a 0 to 10 numerical rating scale of intensity and indicated on the survey that they would be willing to be contacted about possible participation in future research studies.

Exclusion criteria: evidence of severe psychopathology symptoms or psychosis on interview or endorsement of active suicidal ideation with intent within the past 6 months, score of 21 or greater on the Telephone Interview of Cognitive Status indicative of severe cognitive deficits that could potentially interfere with the focused attention required for hypnosis.

Age: mean age 51.7 years ( $27-75$ years)

Gender: 16 women, 6 men

Type of MS: not reported

Pain type: not reported

Interventions

Intervention: self-hypnosis training

Control: progressive relaxation

Duration: 10 sessions

Primary outcome
Outcomes
Secondary outcomes
- BPI
- Amount and effects of hypnosis (pain relief 0 to 10, number of days listened, usual number of times
listened, hours of relief they experiences after listening)


Conflicts of interest: not reported

\section{Risk of bias}

\begin{tabular}{|c|c|c|}
\hline Bias & Authors' judgement & Support for judgement \\
\hline $\begin{array}{l}\text { Random sequence genera- } \\
\text { tion (selection bias) }\end{array}$ & Low risk & $\begin{array}{l}\text { Participants were randomly assigned via a computer-generated list of random } \\
\text { numbers }\end{array}$ \\
\hline $\begin{array}{l}\text { Allocation concealment } \\
\text { (selection bias) }\end{array}$ & Unclear risk & No allocation concealment described \\
\hline $\begin{array}{l}\text { Blinding of participants } \\
\text { and personnel (perfor- } \\
\text { mance bias) } \\
\text { All outcomes }\end{array}$ & High risk & No blinding reported \\
\hline $\begin{array}{l}\text { Blinding of outcome as- } \\
\text { sessment (detection bias) } \\
\text { All outcomes }\end{array}$ & Low risk & Blinding of assessors \\
\hline $\begin{array}{l}\text { Incomplete outcome data } \\
\text { (attrition bias) } \\
\text { All outcomes }\end{array}$ & Low risk & Two of the participants did not provide complete data \\
\hline $\begin{array}{l}\text { Selective reporting (re- } \\
\text { porting bias) }\end{array}$ & Low risk & All data presented \\
\hline Other bias & Low risk & No other bias detected \\
\hline
\end{tabular}

Jensen 2016

$\begin{array}{ll}\text { Methods } & \text { Randomised controlled trial } \\ \text { - Study conducted in the USA } \\ \text { - Randomisation through computer-generated lists } \\ \text { - Allocation concealment not described }\end{array}$

Participants

Population source: recruited from former participants of an ongoing MS symptom self-management study (who did not receive intervention), University of Washington Medical Center (UWMC) MS Clinic, Harborview and/or UWMC Rehabilitation Clinicand self-referrals from study brochures and flyers.

Numbers: randomised 20, EEG biofeedback (NF-HYP) 10, relaxation control group 10

Incusion criteria: 18 years or older, $>=6$ months post-MS diagnosis, otherwise healthy, daily pain related to their MS that has been present for at least 6 months, average MS pain intensity over the past week of at least 4 on a 0 to 10 numerical rating scale, and able to read, write, and understand English.

Exclusion criteria: history of a seizure disorder, significant psychological or psychiatric disturbance, intermittent pain, hospitalisation or psychiatric reasons in the past 6 months, or failure to pass a cognitive screening test and experiencing an MS exacerbation.

Age: mean age (50 years)

Gender: 12 women, 7 men

Type of MS: relapsing remitting 12 , secondary progressive 5 , primary progressive 0 , progressive relapsing 0 , unknown 2 
Jensen 2016 (Continued)

\section{Pain type: not reported}

Adverse effects: not reported
Intervention: hypnosis preceded by neurofeedback

Control: hypnosis preceded relaxation

Duration: 5 sessions of self-hypnosis training ( 1 face-to-face and 4 pre-recorded sessions

Neurofeedback: 20 minutes of neurofeedback

Relaxation: 20 minutes of relaxation through headphones

Primary outcomes
- Average NRS
Secondary outcomes
- NRS (Worst pain intensity)
- FSS
- BPI

Notes

Funding: not reported

Conflicts of interest: not reported

\section{Risk of bias}

\begin{tabular}{|c|c|c|}
\hline Bias & Authors' judgement & Support for judgement \\
\hline $\begin{array}{l}\text { Random sequence genera- } \\
\text { tion (selection bias) }\end{array}$ & Low risk & Randomisation through computer-generated numbers \\
\hline $\begin{array}{l}\text { Allocation concealment } \\
\text { (selection bias) }\end{array}$ & Unclear risk & No allocation concealment described \\
\hline $\begin{array}{l}\text { Blinding of participants } \\
\text { and personnel (perfor- } \\
\text { mance bias) } \\
\text { All outcomes }\end{array}$ & Unclear risk & Blinding was not described \\
\hline $\begin{array}{l}\text { Blinding of outcome as- } \\
\text { sessment (detection bias) } \\
\text { All outcomes }\end{array}$ & High risk & No blinding for assessors \\
\hline $\begin{array}{l}\text { Incomplete outcome data } \\
\text { (attrition bias) } \\
\text { All outcomes }\end{array}$ & Low risk & One participant's data not collected \\
\hline $\begin{array}{l}\text { Selective reporting (re- } \\
\text { porting bias) }\end{array}$ & Low risk & All outcomes reported \\
\hline Other bias & Low risk & No other bias detected \\
\hline
\end{tabular}


Mori 2010

\begin{tabular}{ll}
\hline Methods & Randomised controlled trial and double-blinded \\
- Study conducted in Italy \\
- Randomisation through computer-generated lists \\
- Allocation concealment not described
\end{tabular}

Participants

Population source: randomised 19 intervention group (transcranial direct current stimulation) 10, control 9

Inclusion criteria: diagnosis of MS established by Mcdonalds Criteria, chronic neuropathic pain $>1$ month (stereotyped neurological distribution and superficial location), VAS >= 4

Exclusion criteria: pain relating to spasticity

Age: mean age 44.8

Gender: women 11 , men 8

Pain type: neuropathic pain

Type of MS: not reported

\begin{tabular}{ll}
\hline Interventions & Treatment: anod \\
& Control: sham tD \\
& Duration: 5 cons \\
\hline Outcomes & - VAS (Pain) \\
& - VAS (Anxiety) \\
& - SFMPQ \\
& MSQOL54 \\
& BDI
\end{tabular}

Notes

Funding: none to declare

Conflicts of interest: none to declare

\section{Risk of bias}

\begin{tabular}{lll}
\hline Bias & Authors' judgement & Support for judgement \\
\hline $\begin{array}{l}\text { Random sequence genera- } \\
\text { tion (selection bias) }\end{array}$ & Low risk & Randomisation list generated by a computer software \\
\hline $\begin{array}{l}\text { Allocation concealment } \\
\text { (selection bias) }\end{array}$ & Unclear risk & Allocation concealment not described \\
\hline $\begin{array}{l}\text { Blinding of participants } \\
\text { and personnel (perfor- } \\
\text { mance bias) } \\
\text { All outcomes }\end{array}$ & Low risk & Patients and assessing physician were blinded to group allocation \\
\hline $\begin{array}{l}\text { Blinding of outcome as- } \\
\text { sessment (detection bias) }\end{array}$ & Low risk & \\
$\begin{array}{l}\text { All outcomes } \\
\text { Incomplete outcome data } \\
\text { (attrition bias) }\end{array}$ & Low risk & Patients and assessing physician were blinded to group allocation \\
All outcomes & & \\
\hline \hline
\end{tabular}

Non-pharmacological interventions for chronic pain in multiple sclerosis (Review) 
Mori 2010 (Continued)

Selective reporting (re- Low risk All outcomes in the review reported
porting bias)

Other bias Low risk No other bias detected

Nazari 2016

\begin{tabular}{ll}
\hline Methods & Randomised controlled trial,single-blinded \\
- Study conducted in Iran \\
- Randomisation through computer-generated lists \\
- Allocation concealment not described
\end{tabular}

Participants

Population source: MS patients referred to the Clinic of Ayatollah Kashani Hospital (Isfahan, Iran) in 2014,

Numbers: randomised 75 ; relaxation 25 , reflexology 25 , control 25

Inclusion criteria: female, definite diagnosis of MS, 18-75 years of age, healthy legs, not suffering from diseases other than MS, willing to participate in the study, not having a drug addiction, not being pregnant, not being medical staff, feeling chronic pain in at least one body organ, having a history of pain medication use, NRS $>=4$ for at least 6 months, expanded disability status scale of 0 to 7.5

Exclusion criteria: receiving other complementary and alternative treatment during the study period and reflexology treatment,receiving formal training and practicing relaxation in the previous 6 months, acute relapse 1 month preceding or during the study period, not wanting to continue their co-operation in the research

Age: reflexology group (mean 34.4), relaxation (mean 33.9), control group (mean 34.4)

Gender: female only

Type of MS: relapsing remitting (reflexology $88 \%$, relaxation $84 \%$, control $80 \%$ )

Interventions Treatment: relaxation(Audio tape guided relaxation), reflexology (general reflexology massage technique)

Control: routine care 4 weeks

Duration: twice a week, each session lasting 40 minutes

\begin{tabular}{ll}
\hline Outcomes & Pain (NRS) \\
\hline Notes & $\begin{array}{l}\text { Funding: research conducted under financial support of the Vice Chancellor for Research of Isfahan } \\
\text { University of Medical Sciences. }\end{array}$
\end{tabular}

Conflicts of interest: none to declare

\begin{tabular}{lll}
\hline Risk of bias & \\
\hline Bias & Authors' judgement & Support for judgement \\
\hline $\begin{array}{l}\text { Random sequence genera- } \\
\text { tion (selection bias) }\end{array}$ & Low risk & $\begin{array}{l}\text { Participants were randomly assigned, using minimisation method with MiniPy } \\
\text { software }\end{array}$ \\
\hline $\begin{array}{l}\text { Allocation concealment } \\
\text { (selection bias) }\end{array}$ & Unclear risk & Allocation concealment not described \\
\hline
\end{tabular}


Nazari 2016 (Continued)
Blinding of participants
Unclear risk
Did not describe which group was blinded and personnel (performance bias)

All outcomes

\begin{tabular}{|c|c|c|}
\hline $\begin{array}{l}\text { Blinding of outcome as- } \\
\text { sessment (detection bias) } \\
\text { All outcomes }\end{array}$ & Unclear risk & Did not describe which group was blinded \\
\hline $\begin{array}{l}\text { Incomplete outcome data } \\
\text { (attrition bias) } \\
\text { All outcomes }\end{array}$ & Low risk & None lost to follow-up \\
\hline $\begin{array}{l}\text { Selective reporting (re- } \\
\text { porting bias) }\end{array}$ & Low risk & All outcomes reported \\
\hline Other bias & Low risk & $\begin{array}{l}\text { The funding organisation(s) played no role in the study design; in the collec- } \\
\text { tion, analysis, and interpretation of data; in the writing of the report; or in the } \\
\text { decision to submit the report for publication. }\end{array}$ \\
\hline
\end{tabular}

\section{Palm 2016}

$\begin{array}{ll}\text { Methods } & \text { Randomised controlled, cross-over, double-blinded trial } \\ \text { - Study conducted in France } \\ \text { - Randomisation method not discussed } \\ \text { - Allocation concealment not discussed }\end{array}$

Participants

Population source: MS patients recruited from inpatient and outpatient neurology departments at Henri Mondor hospital, Creteil,France.

Numbers: randomised 16 (not reported number in each group)

Inclusion criteria: age 18-70 years of age, right-handedness as per Edinburgh Inventory, a definitive diagnosis of MS according to McDonalds Criteria, presence of neuropathic pain as per neuropathic pain symptom inventory $>3$ months, VAS (0-100) $>40 \mathrm{~mm}$ on a daily basis during a representative week, stable pharmacological and physical therapies since at least 1 month, the presence of measurable pain related evoked potentials at the right hand, the absence of MS relapses within the last 2 months and other neurological or psychiatric conditions.

Exclusion criteria: patients unable to perform the attention network test, deficits in visual fields or severe upper limb impairment based on medical research council scale score of less than 12

Age: mean age 47.4 years, age range $38-64$ years

Gender: 13 women, 3 men

Type of MS: 11 relapsing remitting, 4 secondary progressive, 1 primary progressive

Pain type: neuropathic pain

Adverse effects: phosphenes ( 1 sham),insomnia ( 6 sham, 5 treatment), nausea ( 4 sham, 2 treatment), headache (1 sham)

Duration: 3 daily consecutive sessions of sham or tRNS 
Palm 2016 (Continued)

$\begin{array}{ll}\text { Outcomes } & \text { VAS } \\ & \text { BPI } \\ & \text { - ATN } \\ & \text { HADS } \\ & \text { MFIS } \\ & \text { PREP } \\ \text { - FMTA }\end{array}$

Notes

Funding: received grants

Conflicts of interest: none

\section{Risk of bias}

\begin{tabular}{|c|c|c|}
\hline Bias & Authors' judgement & Support for judgement \\
\hline $\begin{array}{l}\text { Random sequence genera- } \\
\text { tion (selection bias) }\end{array}$ & Unclear risk & Randomisation not discussed \\
\hline $\begin{array}{l}\text { Allocation concealment } \\
\text { (selection bias) }\end{array}$ & Unclear risk & Allocation concealment not described \\
\hline $\begin{array}{l}\text { Blinding of participants } \\
\text { and personnel (perfor- } \\
\text { mance bias) } \\
\text { All outcomes }\end{array}$ & Low risk & Blinding was achieved \\
\hline $\begin{array}{l}\text { Blinding of outcome as- } \\
\text { sessment (detection bias) } \\
\text { All outcomes }\end{array}$ & Unclear risk & Blinding of assessors was not described, or if it was achieved. \\
\hline $\begin{array}{l}\text { Incomplete outcome data } \\
\text { (attrition bias) } \\
\text { All outcomes }\end{array}$ & Low risk & None lost to follow-up \\
\hline $\begin{array}{l}\text { Selective reporting (re- } \\
\text { porting bias) }\end{array}$ & Low risk & All outcomes reported \\
\hline Other bias & Unclear risk & Received grants, not discussed if affected results. \\
\hline
\end{tabular}

Warke 2006

\begin{tabular}{ll}
\hline Methods & Randomised controlled trial, single-blinded \\
- Study conducted in Northern Ireland \\
- Randomisation through computer-generated lists \\
- Allocation concealment not described
\end{tabular}


Warke 2006 (Continued)

Exclusion criteria: comorbidity including serious spinal pathology or psychosocial risk factors,or both, acute MS relapse 1 month preceding or during the trial period,any contraindication to TENS, judged not competent to give informed consent, analgesic abuse, sacral pressure ulcers, participation in other research studies within the previous 3 months

Age: range 21-78 years, low frequency (mean 45.6), high frequency (mean 47.8), placebo (mean 48.7)

Gender: low frequency (24 women, 6 men), high frequency (22 women, 8 men), placebo 23 women, 7 men)

Type of MS: not reported

Pain type: low back pain

Treatment: low frequency $(4 \mathrm{hz})$, high frequency $(110 \mathrm{hz})$
Control: placebo TENS
Duration: lumbar spine application, $>=$ twice daily application, 45 minutes for 6 weeks and anytime
pain occurred.

\begin{tabular}{ll}
\hline Outcomes & Primary \\
& - VAS (Average) \\
& MPQ \\
Secondary \\
- VAS (Worst) \\
- RMDQ \\
- BI \\
- RMI \\
\hline
\end{tabular}

Notes

Funding: financial support from MS Society of Great Britain and Northern Ireland

Conflicts of interest: no other conflicts of interest listed

\section{Risk of bias}

\begin{tabular}{lll}
\hline Bias & Authors' judgement & Support for judgement \\
\hline $\begin{array}{l}\text { Random sequence genera- } \\
\text { tion (selection bias) }\end{array}$ & Low risk & Randomisation was achieved using a computer-generated list \\
\hline $\begin{array}{l}\text { Allocation concealment } \\
\text { (selection bias) }\end{array}$ & Unclear risk & Allocation concealment not described \\
\hline
\end{tabular}

\begin{tabular}{|c|c|c|}
\hline $\begin{array}{l}\text { Blinding of participants } \\
\text { and personnel (perfor- }\end{array}$ & Low risk & $\begin{array}{l}\text { The frequencies set on the TENS units were masked and participants were } \\
\text { blind to the treatment group }\end{array}$ \\
\hline
\end{tabular}

mance bias)

All outcomes

Blinding of outcome as- Low risk Investigator allocating each unit to participants was blinded
sessment (detection bias)
All outcomes

Incomplete outcome data Low risk five participants lost to follow-up
(attrition bias)
All outcomes


Warke 2006 (Continued)

Selective reporting (re- Low risk $\quad$ All outcomes reported
porting bias)

Other bias Unclear risk Did not describe if funding had impact on results

ATN: Attention Network Test, BDI: Beck Depression Inventory, BDI2: Becks Depression Inventory 2, BI: Barthel Index, BPI: Brief Pain Inventory, CGI: Clinical Global Impression, CRQ: Comfort Rating Questionnaire,EEG: Electroencephalogram, EDSS: Expanded Disability Status Scale, FMTA: Frontal Midline Theta Activity, FSS: Fatigue Severity Scale, HADS: Hospital Anxiety and Depression Scale, Questionnaire, MFIS: Modified Fatigue Impact Scale, MPQ: McGIll Pain Questionnaire,MS: Multiple Sclerosis, MSIS29: Multiple sclerosis Impact scale 29, MSQOL54: Multiple Sclerosis Quality of Life-54, NRS: Numerical Rating Scale, PAM: Patient Activation Measure, PANAS: Positive and Negative Affect Scale, PHQ-9: Patient Health Questionnaire-9, PREP: Pain Related Evoked Potential, PRI: Pain Rating Index, PPI: Present Pain Intensity, RMDQ: Roland Morris Disability Questionnaire, RMI: Rivermead Mobility Index, SES: Self Efficacy Scale, SF8: Short Form 8 Health Survey, SFMPQ: Short Form McGill Pain Questionnaire, tDCS: Transcranial Direct Current Stimulation, tRNS: Transcranial random noise stimulation, TENS: Transcutaneous Electrical Nerve Stimulation, VAS: Visual Analogue Scale

Characteristics of excluded studies [ordered by study ID]

\begin{tabular}{|c|c|}
\hline Study & Reason for exclusion \\
\hline Anninos 2016 & Pain not an outcome criteria \\
\hline Backus 2016 & Not a clinical controlled trial \\
\hline Barlow 2009 & Pain not an outcome criteria \\
\hline Catena 2014 & Abstract \\
\hline Doulatabad 2012 & Chronic pain not a criteria \\
\hline Hasanpour-Dehkordi 2015 & Chronic pain not a criteria \\
\hline Hasanpour-Dehkordi 2016 & Chronic pain not criteria \\
\hline Jensen 2007 & Abstract \\
\hline Jensen 2011 & Not a controlled clinical trial \\
\hline Marinelli 2015 & Chronic pain not a criteria \\
\hline Mathiowetz 2005 & Chronic pain not a criteria \\
\hline McGuire 2015 & Chronic pain not a criteria \\
\hline Negahban 2013 & Chronic pain not a criteria \\
\hline Oken 2004 & Chronic pain not a criteria \\
\hline Pilutti 2013 & Chronic pain not a criteria \\
\hline Pozzilli 2002 & Chronic pain not a criteria \\
\hline Seada 2013 & Not controlled clinical trial. \\
\hline Smedal 2011 & Chronic pain not a criteria \\
\hline
\end{tabular}




Study Reason for exclusion

Storr $2006 \quad$ Chronic pain not a criteria

Van der Linden $2013 \quad$ Chronic pain not a criteria

\section{APPENDICES}

\section{Appendix 1. Glossary}

- Dorsal column: spinal pathways located at the rear of the spinal cord

- Dysesthesia: an unpleasant abnormal sensation that can occur spontaneously or when touched; the sensation can be felt as pain, burning, wetness, itching, electric shock or 'pins and needles'

- Fibromyalgia: condition characterised by widespread pain; the cause is unknown

- Hypoalgesia: reduced experience of pain to a normally painful stimulus

- Idiopathic pain: pain with a cause that cannot be identified

- Interstitial cystitis: a long-term painful bladder condition also known as 'painful bladder syndrome' or 'bladder pain syndrome'

- Lhermitte phenomenon: a brief electric shock or vibration which runs from the neck down the spine and is uncomfortable

- Neuropathic pain: pain arising because of disease in the nervous system

- Nociceptive pain: pain caused by tissue damage, usually described as a sharp, aching, or throbbing pain.

- Optic neuritis: inflammatory damage to optic nerve (nerve from brainstem) that may lead to complete or partial loss of vision

- Paroxysmal: a sudden occurrence or intensification of symptoms

- Proprioception: the perception of outside stimuli that informs the body of the relative position of its parts

- Psychogenic pain: physical pain that is caused, increased, or prolonged by mental, emotional, or behavioural factors

- Refractory: a disease or condition which does not respond to attempted forms of treatment, for example poor pain of relief after painrelieving medicine

- Somatosensory: sensory system in the body involved in detecting touch, pressure, pain, temperature, movement and vibration

- Thermotherapy: application of heat or cold to the body for pain relief

- Tonic spasms: sudden abnormal muscle contraction

- Transcranial direct cranial stimulation: non-invasive brain stimulation using low currents

- Transmagnetic stimulation: application of brief magnetic pulses that stimulate the brain

- Trigeminal neuralgia: nerve pain involving the trigeminal nerve which is responsible for sensation in the face and for controlling biting and chewing

\section{Appendix 2. Keywords}

\{Pain\} OR \{chronic pain\} OR \{pain management\} OR \{pain intractable\} OR \{pain measurement\} OR \{pain threshold\} OR \{nociceptors\} AND \{rehabilitation \} OR \{exercise\} OR \{exercise therapy\} OR \{physical therapy\} OR \{psychotherapy\} OR \{hydrotherapy\} OR \{complementary therapies\} OR \{transcutaneous electric nerve stimulation\} OR \{transcranial magnetic stimulation\} OR \{dorsal colum stimulation\} OR \{spinal cord stimulation\} OR \{peripheral field stimulation\} OR \{dorsal root entry zone lesion\} OR \{DREZ\}

\section{Appendix 3. PsycINFO}

S1 TX multiple sclerosis

S2 DE "Multiple Sclerosis"

S3 TX demyelinating disease*

S4 DE "Demyelination"

S5 TX transverse myelitis

S6 DE "Myelitis"

S7 TX neuromyelitis optica 
S8 TX optic neuritis

S9 TX encephalomyelitis acute disseminated

S10 DE "Encephalopathies"

S11 TX devic

$\mathrm{S} 12 \mathrm{~S} 1$ or $\mathrm{S} 2$ or $\mathrm{S} 3$ or $\mathrm{S} 4$ or $\mathrm{S} 5$ or $\mathrm{S} 6$ or $\mathrm{S} 7$ or $\mathrm{S} 8$ or $\mathrm{S} 9$ or $\mathrm{S} 10$ or $\mathrm{S} 11$

S13 DE "Somatosensory Disorders"

S14 DE "Pain" OR DE "Aphagia" OR DE "Back Pain" OR DE "Chronic Pain" OR DE "Headache" OR DE "Myofascial Pain" OR DE "Neuralgia" OR DE "Neuropathic Pain" OR DE "Somatoform Pain Disorder"

S15 TX pain

S16 TX central pain

S17 TX dys\#esthesia or TX dys\#esthetic

S18 S13 or S14 or S15 or S16 or S17

S19 TX intractable

S20 DE "Pain Measurement"

S21 DE "Pain Perception"

S22 DE "Pain Thresholds" or DE "Pain Management"

S23 DE "Nociceptors"

S24 AB pain N5 (refer* or refractory or intractable or receptor ${ }^{\star}$ or nocicept* or muskuloskeletal or chronic or intens ${ }^{\star}$ or threshold ${ }^{\star}$ or shoulder $^{\star}$ or abdominal* or back or neuropath ${ }^{\star}$ )

S25 TI pain N5 (refer* or refractory or intractable or receptor* or nocicept* or muskuloskeletal or chronic or intens ${ }^{\star}$ or threshold ${ }^{\star}$ or

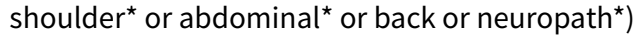

S26 (TI nocicept* N3 neuron*) OR TI pain*

$\mathrm{S} 27 \mathrm{~S} 19$ or $\mathrm{S} 20$ or $\mathrm{S} 21$ or $\mathrm{S} 22$ or S23 or S24 or S25 or S26

S28 S12 and S18 and S27

S29 DE "Rehabilitation" OR DE "Cognitive Rehabilitation" OR DE "Neuropsychological Rehabilitation" OR DE "Neurorehabilitation" OR DE "Occupational Therapy" OR DE "Physical Therapy" OR DE "Psychosocial Rehabilitation"

S30 DE "Exercise" OR DE "Aerobic Exercise" OR DE "Weightlifting" OR DE "Yoga"

S31 TX exercise therap* or TX stretching or TX tai chi or TX yoga

S32 DE "Psychotherapy" OR DE "Adlerian Psychotherapy" OR DE "Adolescent Psychotherapy" OR DE "Analytical Psychotherapy" OR DE "Autogenic Training" OR DE "Behavior Therapy" OR DE "Brief Psychotherapy" OR DE "Child Psychotherapy" OR DE "Client Centered Therapy" OR DE "Cognitive Behavior Therapy" OR DE "Conversion Therapy" OR DE "Eclectic Psychotherapy" OR DE "Emotion Focused Therapy" OR DE "Existential Therapy" OR DE "Experiential Psychotherapy" OR DE "Expressive Psychotherapy" OR DE "Eye Movement Desensitization Therapy" OR DE "Feminist Therapy" OR DE "Geriatric Psychotherapy" OR DE "Gestalt Therapy" OR DE "Group Psychotherapy" OR DE "Guided Imagery" OR DE "Humanistic Psychotherapy" OR DE "Hypnotherapy" OR DE "Individual Psychotherapy" OR DE "Insight Therapy" OR DE "Integrative Psychotherapy" OR DE "Interpersonal Psychotherapy" OR DE "Logotherapy" OR DE "Narrative Therapy" OR DE "Persuasion Therapy" OR DE "Primal Therapy" OR DE "Psychoanalysis" OR DE "Psychodrama" OR DE "Psychodynamic Psychotherapy" OR DE "Psychotherapeutic Counseling" OR DE "Rational Emotive Behavior Therapy" OR DE "Reality Therapy" OR DE "Relationship Therapy" OR DE "Solution Focused Therapy" OR DE "Supportive Psychotherapy" OR DE "Transactional Analysis"

S33 TX cognitive behavio\#ral or TX relaxation or TX breathing or TX hypnosis

S34 DE "Relaxation" OR DE "Relaxation Therapy" OR DE "Progressive Relaxation Therapy" 
S35 DE "Hypnosis" OR DE "Autohypnosis"

S36 TX hydrotherap* or TX thermo* or TX heat or TX warm or TX cold or TX cool

S37 DE "Alternative Medicine"

S38 DE "Acupuncture" OR DE "Aromatherapy" OR DE "Massage" OR DE "Medicinal Herbs and Plants" OR DE "Meditation" OR DE "Osteopathic Medicine"

S39 TX massage or TX chiropractic or TX manipulation or TX acupuncture or TX acupressure or TX osteopath* or TX homeopath* or TX naturopath* or TX aromathera* or TX art or TX music or TX alternative or TX complementary or TX CAM

S40 TX transcutaneous electrical stimulation

S41 DE "Electrical Stimulation" OR DE "Electrical Brain Stimulation" OR DE "Electroconvulsive Shock"

S42 DE "Transcranial Magnetic Stimulation"

S43 TX transcranial magnetic stimulation

S44 TX dorsal column stimulation

S45 TX spinal cord stimulation

S46 TX peripheral field stimulation

S47 TX dorsal root entry zone lesion*

S48 TX DREZ

S49 DE "Osteopathic Medicine"

S50 TX orthotics or TX orthosis or TX brace*

S51 TX nonpharmaco* or TX non-pharmaco*

S52 S29 or S30 or S31 or S32 or S33 or S34 or S35 or S36 or S37 or S38 or S39 or S40 or S41 or S42 or S43 or S44 or S45 or S46 or S47 or $\mathrm{S} 48$ or $\mathrm{S} 49$ or $\mathrm{S} 50$ or $\mathrm{S} 51$

S53 S28 and S52

S54 AB randomi\#ed OR TI randomi\#ed

S55 DE "Clinical Trials"

S56 AB placebo

S57 AB randomly

S58 TI trial

S59 S53 or S54 or S55 or S56 or S57 or S58

S60 S59 andS53

\section{Appendix 4. AMED}

S1 TX multiple sclerosis

S2 (DE "MULTIPLE SCLEROSIS")

S3 TX demyelinating disease*

S4 TX transverse myelitis

S5 TX neuromyelitis optica

S6 TX optic neuritis 
S7 TX encephalomyelitis acute disseminated

S8 (DE "ENCEPHALOMYELITIS")

S9 TX devic

$\mathrm{S} 10 \mathrm{~S} 1$ or $\mathrm{S} 2$ or $\mathrm{S} 3$ or $\mathrm{S} 4$ or $\mathrm{S} 5$ or $\mathrm{S} 6$ or $\mathrm{S} 7$ or $\mathrm{S} 8$ or $\mathrm{S} 9$

S11 (DE "PARESTHESIA")

S12 (DE "PAIN")

S13 TX pain

S14 TX central pain

S15 TX dys\#esthesia or TX dys\#esthetic

$\mathrm{S} 16 \mathrm{~S} 11$ or $\mathrm{S} 12$ or $\mathrm{S} 13$ or $\mathrm{S} 14$ or $\mathrm{S} 15$

S17 (DE "PAIN INTRACTABLE")

S18 (DE "PAIN MEASUREMENT")

S19 (DE "PAIN THRESHOLD")

\section{S20 TX nociceptor*}

S21 AB pain N5 (refer ${ }^{\star}$ or refractory or intractable or receptor ${ }^{\star}$ or nocicept ${ }^{\star}$ or muskuloskeletal or chronic or intens ${ }^{\star}$ or threshold ${ }^{\star}$ or shoulder $^{\star}$ or abdominal* or back or neuropath ${ }^{\star}$ )

S22 TI pain N5 (refer* or refractory or intractable or receptor ${ }^{\star}$ or nocicept* or muskuloskeletal or chronic or intens ${ }^{\star}$ or threshold* or shoulder $^{\star}$ or abdominal* or back or neuropath*)

S23 (TI nocicept* N3 neuron*) OR TI pain*

$\mathrm{S} 24 \mathrm{~S} 17$ or $\mathrm{S} 18$ or $\mathrm{S} 19$ or $\mathrm{S} 20$ or $\mathrm{S} 21$ or $\mathrm{S} 22$ or $\mathrm{S} 23$

S25 S10 and S16 and S24

\section{Appendix 5. MANTIS/Ovid}

1 multiple sclerosis.mp.

2 multiple sclerosis.sh.

3 demyelinating disease ${ }^{\star} . \mathrm{mp}$.

4 demyelinating diseases.sh.

5 transverse myelitis.mp

6 myelitis, transverse.sh.

7 neuromyelitis optica.mp

8 optic neuritis.mp

9 optic neuritis.sh

10 encephalomyelitis acute disseminated.mp

11 encephalomyelitis, acute disseminated.sh

12 devic.mp

131 or 2 or 3 or 4 or 5 or 6 or 7 or 8 or 9 or 10 or 11 or 12

14 paresthesia.sh

Non-pharmacological interventions for chronic pain in multiple sclerosis (Review) 
15 pain.sh

16 pain.mp

17 central pain.mp

18 (dys?esthesia or dys?esthetic).mp.

1914 or 15 or 16 or 17 or 18

20 pain, intractable.sh

21 pain measurement.sh

22 pain threshold.sh

23 nociceptors.sh.

24 (pain adj5 (refer* OR refractory OR intractable OR receptor ${ }^{\star}$ OR nocicept ${ }^{\star}$ OR muskuloskeletal OR chronic OR intens ${ }^{\star}$ OR threshold* OR shoulder $^{\star}$ OR abdominal* OR back OR neuropath $\left.\left.{ }^{\star}\right)\right) \cdot$ ab,ti.

25 ((nocicept* ${ }^{\star}$ dj3 neuron*) OR pain $\left.{ }^{\star}\right)$. ti.

2620 or 21 or 22 or 23 or 24 or 25

2713 or 19 or 26

\section{CONTRIBUTIONS OF AUTHORS}

Bhasker Amatya (BA) and Fary Khan (FK) were involved in all aspects of the protocol. All authors were involved at the review stage.

\section{DECLARATIONS OF INTEREST}

The review authors are clinicians in the field of Physical and Medical Rehabilitation who wish to provide the best possible service to their patients.

BA: has no personal or financial conflicts of interest in the findings of this review.

JY: has no personal or financial conflicts of interest in the findings of this review.

FK: has no personal or financial conflicts of interest in the findings of this review.

\section{SOURCES OF SUPPORT}

\section{Internal sources}

- Department of Rehabilitation Medicine, Royal Melbourne Hospital, Australia.

\section{External sources}

- None, Other.

\section{DIFFERENCES BETWEEN PROTOCOL AND REVIEW}

- A meta-analysis was not possible due to methodological, clinical and statistically heterogeneity of included studies

- Change of number of risk of bias items to include 'other bias' and 'blinding of outcome assessment'.

\section{IN DEX TERMS}

\section{Medical Subject Headings (MeSH)}

Chronic Pain [*therapy]; Exercise Therapy [methods]; Hydrotherapy; Hypnosis; Massage; Multiple Sclerosis [ ${ }^{\star}$ complications]; Musculoskeletal Pain [*therapy]; Neurofeedback; Patient Education as Topic [methods]; Psychotherapy; Quality of Life; Randomized Controlled Trials as Topic; Relaxation Therapy; Transcranial Direct Current Stimulation; Transcutaneous Electric Nerve Stimulation [methods]

\section{MeSH check words}

Humans

Non-pharmacological interventions for chronic pain in multiple sclerosis (Review) 